\title{
Small Semantic Networks in Individuals with Autism Spectrum Disorder Without Intellectual Impairment: A Verbal Fluency Approach
}

\author{
Felicitas Ehlen ${ }^{1,2,3} \cdot$ Stefan Roepke ${ }^{3} \cdot$ Fabian Klostermann $^{1,4} \cdot$ Irina Baskow $^{3,5} \cdot$ Pia Geise $^{3,6} \cdot$ Cyril Belica $^{7}$. \\ Hannes Ole Tiedt ${ }^{1} \cdot$ Behnoush Behnia ${ }^{3}$
}

Published online: 20 March 2020

(c) The Author(s) 2020

\begin{abstract}
Individuals with Autism Spectrum Disorder (ASD) experience a variety of symptoms sometimes including atypicalities in language use. The study explored differences in semantic network organisation of adults with ASD without intellectual impairment. We assessed clusters and switches in verbal fluency tasks ('animals', 'human feature', 'verbs', 'r-words') via curve fitting in combination with corpus-driven analysis of semantic relatedness and evaluated socio-emotional and motor action related content. Compared to participants without ASD $(n=39)$, participants with ASD $(n=32)$ tended to produce smaller clusters, longer switches, and fewer words in semantic conditions (no $p$ values survived Bonferroni-correction), whereas relatedness and content were similar. In ASD, semantic networks underlying cluster formation appeared comparably small without affecting strength of associations or content.
\end{abstract}

Keywords ASD $\cdot$ Verbal fluency $\cdot$ Mental lexicon $\cdot$ Clusters $\cdot$ WCC

Hannes Ole Tiedt and Behnoush Behnia contributed equally to the study.

Felicitas Ehlen

felicitas.ehlen@charite.de

1 Present Address: Department of Neurology, Motor and Cognition Group, Charité - Universitätsmedizin Berlin, Campus Benjamin Franklin (CBF), Hindenburgdamm 30, 12203 Berlin, Germany

2 Present Address: Department of Psychiatry, Jüdisches Krankenhaus Berlin, Heinz-Galinski-Straße 1, 13347 Berlin, Germany

3 Department of Psychiatry, Charité - Universitätsmedizin Berlin, Campus Benjamin Franklin (CBF), Hindenburgdamm 30, 12203 Berlin, Germany

4 Berlin School of Mind and Brain, Humboldt-Universität Zu Berlin, Unter den Linden 6, 10099 Berlin, Germany

5 Department of Psychology, Humboldt-Universität Zu Berlin, Unter den Linden 6, 10099 Berlin, Germany

6 Present Address: Universität Potsdam, Am Neuen Palais 10, 14469 Potsdam, Germany

7 Department of Digital Linguistics, Leibniz-Institut für Deutsche Sprache, R5, 6-13, 68161 Mannheim, Germany

\section{Introduction}

Autism Spectrum Disorder (ASD) is understood as a group of neurodevelopmental disorders characterised by difficulties in social interaction and communication as well as stereotyped patterns of behaviour or restricted interests. Clinical presentation and individual symptom severity are highly variable and range from circumscribed atypicalities with normal or superior intelligence to severe impairments in daily living which can be accompanied by intellectual impairments (American Psychiatric Association 2013; Masi et al. 2017). Difficulties in language (Groen et al. 2008) and motor functions (Fournier et al. 2010) are commonly associated with ASD. During the last decades, prevalence has increased and is currently estimated to be up to 1 in 59 children with a predominance in males (with males being four times more likely to be affected; Baio et al. 2018). While its aetiology is only partially understood, multiple genetic and epigenetic deviations have been identified and are expected to interact with environmental factors (Wiśniowiecka-Kowalnik and Nowakowska 2019). Influential cognitive models tackling the core features of ASD provide evidence for, e.g. executive dysfunction (e.g. Ozonoff 1997), weak central coherence (WCC; Frith 1989), and impaired theory of mind (ToM; Baron-Cohen et al. 1985), each explaining certain but not all 
of the symptoms associated with ASD and possibly acting in combination (Happé and Frith 2006). In this sense, impaired executive functions, including mental flexibility, have been proposed to account for rigid, repetitive, and maladaptive behaviours in individuals with ASD (Ozonoff 1997). The WCC theory proposes a bias towards local over global processing in ASD which may explain superior performance in detail-focussed processing at the expense of generalisation (for a review see Happé and Frith 2006). From a neurofunctional perspective, this bias has been related to a functional underconnectivity of integrative networks in individuals with ASD (Just et al. 2004) and a growing number of neuroimaging studies provide support for aberrant (e.g. Arnold Anteraper et al. 2018; Belmonte 2004; Catani et al. 2016; Ecker et al. 2016; Hong et al. 2019), mainly reduced, connectivity (for a review see Hull et al. 2017) of the involved cerebral networks. ToM captures the idea of being able to perceive social cues, and to derive and interpret other people's mental states, beliefs, and thus intentions (Premack and Woodruff 1978). ToM deficits in persons with ASD have therefore been associated with challenges in social interaction, e.g. regarding the prediction of the other's emotions and actions (Baron-Cohen et al. 1985).

In addition to their implications for social interaction, all three cognitive theories provide explanations for some of the language difficulties described for persons with ASD and shall be outlined below (for reviews see Groen et al. 2008; Martin and McDonald 2003). Clinically, the majority of persons with ASD experience some degree of impaired use and perception of semantics, syntax, pragmatics, i.e. how language is used in a social context (Eales 1993; Fine et al. 2011), and sometimes phonology (Tager-Flusberg et al. 2005; for a review see Groen et al. 2008). The clinical spectrum, however, ranges from a complete inability to acquire speech in a minority of individuals to subtle atypicalities mainly regarding pragmatics in individuals with ASD without intellectual impairment (Kjelgaard and Tager-Flusberg 2001; Tager-Flusberg et al. 2005). Corresponding peculiarities involve the use of less 'typical' words and have therefore been proposed to originate from an atypical structure of lexical associations (Dunn et al. 1996).

Theories on the neural underpinnings of the lexical system have become increasingly complex (e.g. Binder and Desai 2011; Patterson et al. 2007; Rofes et al. 2019) and while a great amount of knowledge has been gained, many issues are still unanswered. There has been a general move away from regionally and functionally circumscribed language areas towards a widely distributed, multi-modal network (e.g. Binder and Desai 2011; Kiefer and Pulvermüller 2012; Labache et al. 2019; Mirman et al. 2015; Patterson et al. 2007; Tremblay and Steven 2017). Separable sub-systems are suggested to serve language production vs. recognition (Mirman et al. 2015), semantic vs. phonologic processing (Hickok and Poeppel 2004; Mirman et al. 2015) as well as syntactic (Rofes et al. 2019) and orthographic (Peleg et al. 2016; Seidenberg and McClelland 1989) processing. In terms of language production, neurolinguistic models have thus suggested multi-level processing including conceptualisation, lexical-semantic access, syntactic and phonological encoding, and articulatory preparation (e.g. Dell 1986; Indefrey and Levelt 2004; Levelt 1999; Walker and Hickok 2016; for a review, see Henry and Crawford 2005) leaving the debate open as to whether the last steps are achieved sequentially (e.g. Indefrey and Levelt 2004; Roelofs et al. 1996; Levelt 1999) or in an interconnected mode (e.g. Dell 1986). There is, however, consensus on the idea of an initial conceptualisation, i.e. the activation of non-verbal representations of an object's sensory, motor, and affective features (encompassing, e.g. shape, use, familiarity, and relationships with other objects; Binder and Desai 2011; Kiefer and Pulvermüller 2012; Levelt 1999; Rofes et al. 2019; Pulvermüller 1999). These featural representations have been proposed to be "stored in semantic memory" (Binder and Desai 2011) in a fashion that modality specific information is connected (Patterson et al. 2007) or gradually converges to form more abstract concepts eventually allowing for lexical-semantic operations (Binder and Desai 2011; Damasio et al. 1994; Rofes et al. 2019). This network structure could account for semantic associations (Rofes et al. 2019) between distinct items which thus share common "conceptual memory traces" (Kiefer and Pulvermüller 2012), including perceptual features (e.g. the feature 'furry' could be shared by 'cat' and 'rabbit') as well as individual values (e.g. the feature 'safe' could be shared by 'work' and 'home'; cf. Murphy and Medin 1985). Within this system, prefrontal functions should enable access to, selection of, and shifting between the thus stored semantic knowledge (Mirman et al. 2015; Binder and Desai 2011).

Against this background, executive dysfunction in individuals with ASD could entail a less flexible shift away from one focus to another (Kleinhans et al. 2005; Ozonoff et al. 2007) thus impeding a swift flow of language (Martin and McDonald 2003). Impaired ToM, on the other hand, may account for pragmatic difficulties in individuals with ASD via reduced meta-representational capacities (Baron-Cohen 1988), such as abstraction and presupposition (Boucher 2003; Eales 1993; Helen Tager-Flusberg and Sullivan 1995; Martin and McDonald 2003). Moreover, a crucial overlap between brain regions involved in social cognition and the semantic network has been proposed as a neural connection between impaired ToM and semantic difficulties (Binder and Desai 2011; Groen et al. 2008). From the viewpoint of WCC, semantic deviations in persons with ASD could be theorised as sequalae of weak integrative functions within the semantic network (Huemer and Mann 2010; Nation 1999; Happé and Frith 
2006). Likewise, pragmatic deviations have been discussed as reduced contextual integration of the social features of an utterance (Happé and Frith 2006; Martin and McDonald 2003). Moreover, underconnectivity between frontal and parietal areas in individuals with ASD during sentence comprehension first suggested an association between WCC and functional hypoconnectivity within the language system (Just et al. 2004). Specific implications for language production have been indicated by functional connectivity and tractography studies suggesting a general (Verly et al. 2014) as well as region specific (Verly et al. 2014; Knaus et al. 2010) hypoconnectivity involving various frontal and temporal language regions during word production tasks.

From the above considerations on how mental representations presumably shape the semantic network, it appears plausible that difficulties in social interaction could particularly affect language use involving social interactions or emotional references (Binder and Desai 2011). Corresponding clinical studies, however, yielded controversial results indicating both impaired (Begeer et al. 2010; Brown et al. 2012) and unaffected (Bang et al. 2013; Helen TagerFlusberg and Sullivan 1995) socio-emotional language use.

Similarly, hypothesising an embedding of the semantic network in the sensorimotor system (e.g. Kiefer and Pulvermüller 2012; Pulvermüller 1999; Rofes et al. 2019), a vulnerability of motor action related language to motor impairments has been proposed (Neininger and Pulvermüller 2001 cf. Aravena et al. 2014). Considering the high prevalence of motor symptoms in individuals with ASD (for a meta-analysis see Fournier et al. 2010), particular difficulties in the production of motor action words could thus be expected.

Against this theoretical background, the present study aimed to assess group differences in Verbal Fluency (VF) tasks that could allow conclusions on semantic network organisation, executive functions, or content specific peculiarities in adults with ASD without intellectual impairment vs. non-ASD.

During VF tasks, participants are asked to produce as many words as possible belonging to a predefined semantic category within a limited amount of time (Bousfield and Sedgewick 1944). In so doing, speakers will naturally alternate between rapid production of closely associated words (i.e. 'clusters') and pauses between less connected words (i.e. 'switches') (Gruenewald and Lockhead 1980). Whereas the former is thought to result from an automatic spreading activation between closely related items (Collins and Loftus 1975; Roelofs 1992), the ability to switch is seen as a frontal executive function enabling strategic retrieval (Troyer et al. 1997; Turner 1999). Constraining the VF condition to a particular initial letter (i.e. 'letter fluency') instead of a semantic category (i.e. 'semantic fluency') requires a search strategy based on orthographic properties (Birn et al. 2010), while suppressing automatic but inappropriate semantic coactivation (Robinson et al. 2012; Vonberg et al. 2014).

So far, studies on VF performance including clustering and switching in individuals with ASD without intellectual impairment are rare and have reported partly contradictory findings (Begeer et al. 2014; Inokuchi and Kamio 2013; Spek et al. 2009; Turner 1999): corresponding analyses showed reduced word production in semantic and letter fluency (Spek et al. 2009; Turner 1999) with smaller (Turner 1999) or similar cluster sizes (Spek et al. 2009), specific semantic deficits (Inokuchi and Kamio 2013) as well as longer switches with unimpaired overall word production (Begeer et al. 2014) compared to individuals without ASD. All of these studies used a paradigm based on established semantic subcategories (Troyer et al. 1997) to define semantic clusters. Alternatively, temporal cluster analysis allows for an identification of clusters and switches independently from a-priori defined semantic subcategories by means of their temporal patterning using a curve fitting approach (Bousfield and Sedgewick 1944; Ehlen et al. 2016; Gruenewald and Lockhead 1980). To this end, consecutive words are plotted as a function of time such that 'temporal clusters' correspond to curve sections with a steeper slope than predicted by the formula's graph, i.e. a faster production rate (see Fig. 1a).

In the current study, we combined a temporal cluster analysis with co-occurrence data from a corpus-driven database (Belica 2001) to estimate semantic relatedness within and outside of clusters. To this end, we assessed the co-occurrence value between each two consecutive words and connected the respective values to the word position within vs. outside a cluster for each participant. A high co-occurrence value indicates that two words typically occur in the same context and can thus be expected to be semantically related, whereas a low value should be indicative of low semantic relatedness (Smadja 1989). Higher values within than outside of clusters should therefore be expected. Furthermore, whereas co-occurrence data refer to a corpus, i.e. shared common knowledge, the words produced by the speaker during VF presumably reflect individual associations (cf. Murphy and Medin 1985). Individually low co-occurrence values within clusters could therefore be interpreted as atypical semantic associations.

From this perspective, the following parameters were deemed to be meaningful regarding semantic network organisation and executive functions: semantic relatedness (i.e. co-occurrence value) should provide an estimate of the typicality of associations, 'cluster size' (i.e. number of words per cluster) should represent the scope of densely connected words, 'intracluster time' (i.e. time between consecutive words within a cluster) the respective strength between established associations, the 'number of switches' should relate to the number of accessible items (either single 


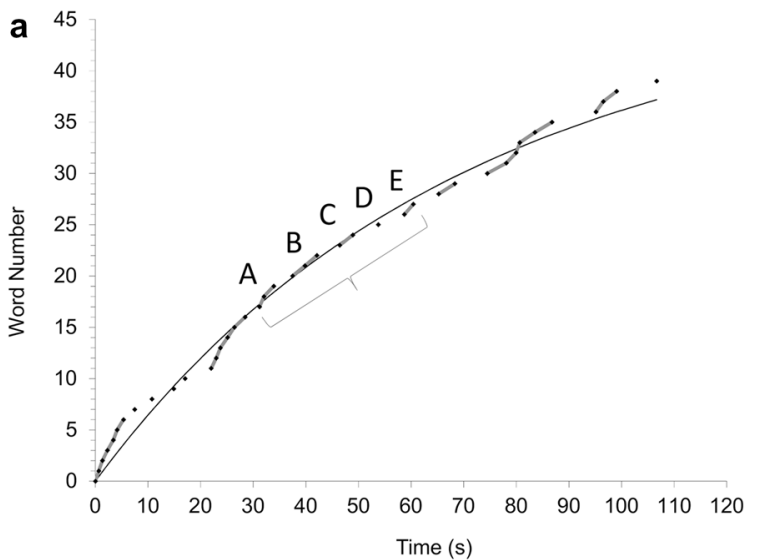

C

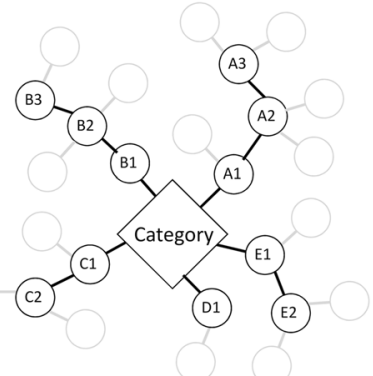

e

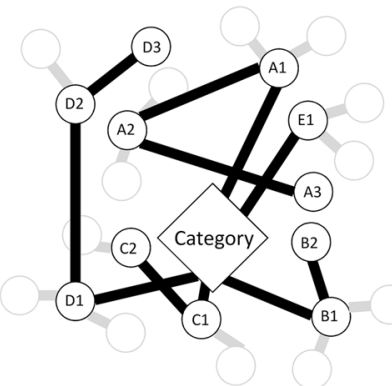

b

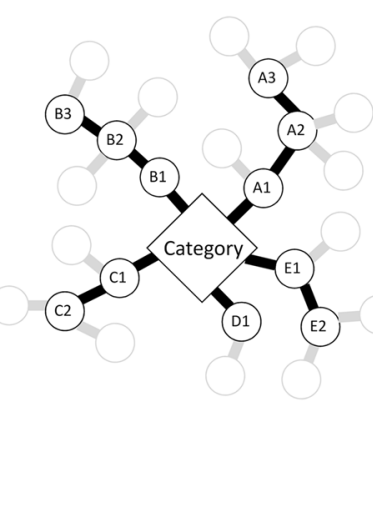

d
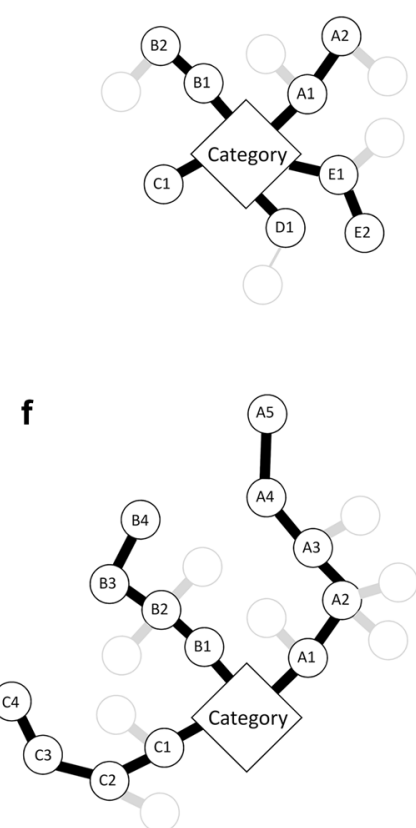

words or clusters) and 'switch duration' (i.e. time between two words not belonging to the same cluster) to their accessibility (see Fig. 1b).

For individuals with ASD, hypoconnectivity within the semantic network could therefore be expected to either cause longer intracluster times as an expression of weaker interitem associations (see Fig. 1c) or reduced cluster sizes as an expression of a lower number of densely connected words (see Fig. 1d). Individual deviations of semantic associations (cf. Dunn et al. 1996), should be indicated by a lower semantic relatedness (i.e. lower co-occurrence value; see Fig. 1e) within clusters. Longer and fewer clusters could, on the other hand, be indicative of reduced set shifting leading to a longer attachment to the present cluster (see Fig. 1f; cf. Reverberi et al. 2006). Lastly, longer and fewer switches could hint at a slower access to new semantic fields (not depicted; cf. Troyer et al. 1997; Turner 1999).

In addition to semantic relatedness, orthographic relatedness was assessed between each two consecutive words within and outside of clusters. This was done under the premise that a bias towards a detail-focussed pattern processing (Huemer and Mann 2010; Nation 1999) could account for an advantage in orthographic processing among individuals with ASD without intellectual impairment (Huemer and Mann 2010; Minshew et al. 1994; Nation 1999; Saldaña et al. 2009). Finally, to test if the ASD group produces fewer socio-emotional and motor action words than the non-ASD group, we introduced the semantic categories 
4Fig. 1 Semantic Network Model. a, b Model of typical network function: By means of curve fitting, consecutive words (word number on the ordinate) are plotted as a function of time (starting time in seconds on the abscissa). Applying a slope difference algorithm, temporal clusters (e.g. clusters A, B, C, D, E) with a faster production rate can be differentiated from slower switches. As exemplified by clusters A-E, word retrieval can be understood as an activation of the task category (rhombus) followed by an automatic activation of the first cluster of closely related words (A1-A2-A3). Noteworthy, due to task constraints the number of uttered words (black circles) does not necessarily represent the number of all mental associations (black + grey circles). If, e.g. the words 'pig-horse-cow' were correctly retrieved as belonging to the category 'animals', the association 'stable' would have to be suppressed. Once a cluster has ended, a switch will occur during which a new word will be actively searched, leading to either the activation of another cluster (B1-B2-B3) or another switch (D1). 'Cluster size' (i.e. number of words per cluster) is thus a marker for the scope of densely related words; 'intracluster time' (i.e. intervals between consecutive words within the same cluster) a marker for strength of established associations between lexical items; 'number of switches' a marker for accessible items in a given amount of time, and 'switch duration' (i.e. interval between two words not belonging to the same cluster) a marker for accessibility. Semantic relatedness (i.e. co-occurrence value) should be related to the typicality of semantic associations. c Model of weaker semantic associations: Due to less efficient automatic activation, longer intracluster times with unaltered cluster size should be expected. Consequently, fewer switches within the given amount time should occur. Due to a preserved overall organisation of associations, semantic relatedness should not be affected. d Model of fewer densely connected words: Smaller cluster sizes should represent a lower number of highly associated words and go along with unaltered intracluster time, switch duration, and semantic relatedness. e Model of atypical associative pattern: Deviations from the typical organisation of semantic associations should lead to a lower semantic relatedness. f Model of impaired set shifting function: Reduced set shifting as an executive dysfunction should lead to longer attachment to a cluster rendering larger clusters, fewer switches and a higher overall semantic relatedness

'human features' and 'verbs' along with a semantic control condition (i.e. 'animals'). In addition to the above-named measures, both categories underwent an analysis of their semantic content (not performed for the other two conditions under the idea that they do not specifically convey socioemotional or motor action related content).

\section{Summary of Study Hypothesis}

The primary focus of the current study was to compare lexical network functions between adults with and without ASD without intellectual impairment by means of VF analysis. In this regard, we expected lower semantic relatedness within clusters as a marker for atypical semantic associations, longer intracluster times to indicate weaker interitem associations, and smaller clusters as a marker for a lower number of densely connected words for the ASD vs. non-ASD group. These differences were predicted to occur mainly in the three semantic task conditions as opposed to the letter fluency condition. Conversely, higher orthographic relatedness as a marker for advanced orthographic processing in the ASD vs. non-ASD group appeared feasible. Lastly, potential difficulties of the ASD group to produce words conveying socioemotional or motor action related content were assessed by a semantic analysis of the task conditions 'features' and 'verbs'.

\section{Methods}

\section{Participants}

Female and male adults with ASD $(n=32)$ as well as individuals without ASD (referred to as 'non-ASD'; $n=39$ ) were recruited for the current study, which was part of the Autect-Study (Cho et al. 2020). Exclusion criteria were IQ below 85 to ensure the comprehension of the instructions, current antipsychotic or anticonvulsant medication to eliminate potential neurological side effects, non-native German speakers, comorbid neurological disorders (i.e. demyelinating, neurodegenerative, or vascular disorders such as multiple sclerosis, Parkinson's disease, Huntington's disease, or Alzheimer's disease or a history of stroke), and age over 65 years to avoid possible confounding age-related neurodegeneration. In the non-ASD group, a history of any psychiatric disorder or Autism Spectrum Quotient (AQ Baron-Cohen et al. 2006; ) above 32 points were exclusionary. According to their self-reported family histories, none of the non-ASD participants had a first-degree relative with ASD.

All participants with ASD were recruited via the ASD outpatient clinic of our university hospital. The non-ASD group was recruited from the PESA (Psychological Experimental Server Adlershof) database and via postings.

The ASD diagnostic process was performed by an expert in the field based on clinical interviews and scale assessments, encompassing a structured interview according to DSM-5 as well as the Autism Diagnostic Observation Schedule (ADOS, module 4 (Lord et al. 1989; Rühl et al. 2004) to quantify atypicalities in social and communicative behaviour by means of structured and semi-structured tasks. The Autism Diagnostic Interview-Revised (ADI-R; Lord et al. 1994; Bölte and Poustka 2005) was additionally conducted if a parent was available $(n=21)$. An ASD diagnosis was given if an individual fulfilled all required DSM-5 criteria. Participants from both groups were furthermore tested for tendency towards autistic-like traits using the AQ consisting of fifty questions (scores below 26 points indicate few or no autistic traits; scores above 25 are indicative, and scores above 32 are highly predictive of ASD). We used the "Wortschatztest" (WST; i.e. "vocabulary test") (Schmidt and Metzler 1992) to assess the verbal intelligence quotient (VIQ) in all participants. The WST requires the recognition of 42 increasingly complex target words, each of which is 
presented in a list of five distractor pseudowords (e.g. "Sebtion-Pavisol-Arkusion-Epuktion-Savasor-Eruption"; Eruption being the target word). Test execution requires approximately $10 \mathrm{~min}$. The test correlates highly with the Wechsler Adult Intelligence Scale, such that it can be used to estimate crystallized intelligence (Satzger et al. 2002).

All interviews and tests were carried out by specially trained psychologists and psychiatrists.

Participants from both groups did not differ significantly with respect to age, sex, or verbal IQ; as expected, a large difference was found regarding the AQ (see Table 1 for an overview).

\section{Material}

\section{Verbal Fluency Tasks}

All participants performed a Verbal Fluency (VF) test based on the German standard VF "Regensburger Wortfluessigkeitstest" (Aschenbrenner and Tucha Lange 2001). The test requires participants to produce as many words as possible pertaining to either a predefined semantic category (i.e. semantic fluency) or commencing with a given letter (i.e. letter fluency) within $120 \mathrm{~s}$.

\section{Design}

\section{General}

The dependent variables total number of words, cluster size, intracluster, number of switches, switch duration, semantic relatedness, orthographic relatedness, and semantic category (please see Procedures for details) were analysed by means of separate linear mixed models (LMMs) detailed below. Acknowledging the fundamental differences between semantic and letter based retrieval processes (Birn et al. 2010; Robinson et al. 2012; Vonberg et al. 2014) outlined in the Introduction, the analyses were performed separately for semantic and letter fluency task conditions (i.e. the three semantic task conditions were collapsed per LMM analysis; the letter fluency condition was analysed separately).

Due to processing speed-mediated effects of age on VF performance (Elgamal et al. 2011), subject outliers were assessed using Cook's distances (age as independent; 'number of words' as dependent variable) separately for both groups prior to the main analyses. Values were considered as relevant if individual Cook's distance exceeded three times the mean value and subjects were excluded if relevantly elevated values were detected in more than one task condition.

Data contribution was assessed using the Kolmogorov-Smirnov test. All statistical operations were carried out using the software IBM SPSS Version 25.

\section{Speech Velocity}

In advance of the main analyses, we compared average word lengths between both groups via t-test to control for group differences in speech velocity.

\section{Verbal Fluency Performance, Semantic Fluency}

Five separate LMMs were performed to evaluate effects of group and task condition on the five dependent parameters total number of words, cluster size, intracluster time, number of switches, and switch duration across all three semantic task conditions. For each LMM group and task condition served as main fixed factors. The variables sex and age were included as covariates.

\section{Verbal Fluency Performance, Letter Fluency}

The same five dependent variables were assessed in five separate linear mixed models each with the main fixed factor group and the covariates sex and age.
Table 1 Overview participants: the table provides mean values and standard deviations (SD) from participants with Autism Spectrum Disorder (ASD) and without (non-ASD) regarding age, verbal intelligence quotient (VIQ), and the autism spectrum quotient (AQ; values
$<25$ are indicative of no autistic traits, values $>32$ are highly predictive of ASD) as well as the distribution of female and male participants

\begin{tabular}{|c|c|c|c|c|c|c|c|}
\hline & \multicolumn{2}{|l|}{ ASD } & \multicolumn{2}{|l|}{ Non-ASD } & \multirow[t]{2}{*}{$p$ value } & \multirow[t]{2}{*}{$F_{1,69}$} & \multirow[t]{2}{*}{ Cohen's $d$} \\
\hline & Mean & $S D$ & Mean & $S D$ & & & \\
\hline Age (years) & 37.063 & 10.692 & 34.974 & 7.768 & .344 & .906 & -.223 \\
\hline Sex & f: $14 ;$ m: 18 & & $\mathrm{f:} 22 ; \mathrm{m}: 17$ & & 2.880 & & \\
\hline VIQ (points) & 111.452 & 11.463 & 103.744 & 34.778 & .241 & .350 & -.298 \\
\hline $\mathrm{AQ}$ (points) & 37.290 & 5.751 & 14.314 & 6.173 & $<.001$ & 242.758 & -3.851 \\
\hline ADOS (points) & 9.188 & 3.247 & & & & & \\
\hline
\end{tabular}

ADOS scores were not assessed in the non-ASD group. Group differences were generally tested using $t$ tests except for the dichotomous parameter sex (chi-squared test). Cohen's $d$ was computed only for significant parameters 


\section{Semantic and Orthographic Relatedness, Semantic Fluency}

To assess semantic relatedness within vs. outside of clusters across all three semantic task conditions, a LMM was applied using the dependent variable semantic relatedness and the main fixed factors group, task condition, and word position within vs. outside of clusters. Sex and age served as covariates.

Orthographic relatedness was assessed with the same approach in a separate LMM.

\section{Semantic and Orthographic Relatedness, Letter Fluency}

In the letter fluency condition, semantic relatedness served as dependent variable, group and word position within vs. outside of clusters as main fixed factors and sex and age as covariates. Orthographic relatedness was assessed similarly in a separate LMM.

\section{Semantic Content}

With respect to 'human features', we used a LMM with number of words as dependent variable and the main factors semantic category (i.e. 'external features', 'human dispositions/feelings', 'other') and group. The same model was applied regarding the semantic content of 'verbs' (i.e. 'intentional physical actions', 'inactive states', 'mental actions', and 'non-action verbs').

\section{Error Rates}

Kruskal-Wallis analyses for non-normally distributed data were used to evaluate group differences between the total number of errors (expressed as percentage value of the respective total number of words) per task condition.

\section{Level of Significance and Effect Sizes}

Altogether 16 LMMs were computed to assess the study outcome parameters. Therefore, Bonferroni correction yielded an adjusted level of significance of $p<.003$ (applicable to the main effects and interactions of each LMM). Regarding demographic and symptom related data (i.e. word length, age, verbal IQ, AQ, and sex) the adjusted level of significance was $p<.01$. The adjusted level of significance for Pearson's correlation was $p<.008$. Since the use of Bonferroni procedures increases the probability of Type II errors, potentially informative effects could be missed (Nakagawa 2004). We therefore report $p$ values obtained from the single statistical evaluations along with measures of effect sizes (cf. Wasserstein and Lazar 2016). Since there is no unequivocal effect size index for LMM (Lüdecke 2017), we used Cohen's $d$ (>.2: small; $>$.5: medium; $>.8$ : large effect size; Cohen 1988b) for main fixed factors with two levels (i.e. group and word position within vs. outside of clusters) and eta squared $\left(\eta^{2}>.01\right.$ : small; $>.06$ : medium; $>.14$ : large effect size; Cohen 1988a) obtained from univariate ANOVAs for main fixed factors with more than two levels (i.e. task condition and semantic category), covariates, and non-normally distributed data (i.e. errors). Furthermore, when a LMM indicated an effect of group, correlations were carried out between the dependent variable and the AQ.

\section{Procedure}

\section{Verbal Fluency Task}

Participants were instructed to avoid repetitions of whole words, word stems, and proper names. Semantic fluency comprised the three categories 'animals', 'human features' and 'verbs'. Whereas the first category served as control condition, the other two served to assess group differences specifically related to the socio-emotional or motor action related semantic content. For letter fluency, the common starting letter ' $r$ ' was chosen. The order of all four tests was randomised. Samples were digitally recorded (computer software Audacity 1.3.13-beta), annotated and analysed acoustically and visually using Praat software (version 6.0.40) by determining the starting and ending point of each uttered word (i.e. 'word length' in seconds with three decimal places). Metacomments (e.g. 'I can't come up with more words') were not included in the analysis, while errors were assumed to be of informative value (cf. Troyer et al. 1997).

\section{Verbal Fluency Performance}

In order to evaluate clusters and switches, the individual data underwent a curve fitting process using the power function $n$ $(t)=c \cdot\left[1-(1+\alpha \cdot r \cdot t / c)^{-1 / \alpha}\right]$ established specifically for $\mathrm{VF}$ analysis (with $n$ : number of words produced; $t$ : time (in seconds); $c$ : asymptote (in words); $\alpha$ : shape parameter (dimensionless); $r$ : initial rate (in words/min) Ehlen et al. 2016;). To this end, the starting point of each word was plotted as a function of time (word number on the ordinate; starting time in seconds on the abscissa) for each participant and condition. In accordance with the slope-difference algorithm (Gruenewald and Lockhead 1980), clusters were defined as two or more consecutive words produced at a faster rate than predicted by the individual graph, whereas switches were defined as slower transitions between two clusters (see Fig. 1a). Thus defining clusters as relative to the individual production curve, a person's overall response speed does generally not impact on the distinction between clusters and switches.

We determined the total number of words, cluster size (i.e. number of words per cluster), intracluster time (i.e. 
average duration from word onset to next word onset within clusters), number of switches, and switch duration (i.e. average duration from word onset to next word onset of switches).

\section{Semantic Relatedness}

Semantic relatedness is generally assumed if two items typically occur in the same context, such that co-occurrence analyses of textual data have been established to assess the strength of semantic relatedness (Smadja 1989). In the current study semantic relatedness between each two consecutive words was evaluated using the corpus-driven cooccurrence database (CCDB) of the Leibniz Institute for the German Language (Belica 2001). The database includes information extracted from a corpus of about 2.2 billion running words forming a collection of co-occurrence profiles of about 222,000 different lemmas (Belica 1995). Semantic relatedness is expressed by a size between 0 (i.e. no relatedness) and 1 (identity) with an accuracy of 6 decimal places. For this purpose, all words were converted into their lemma form. If a word was not included in the database, it was substituted by the closest related word found in the CCDB (e.g. 'brown bear' instead of 'grizzly bear'). In total, 133 out of 3604 words $(3.690 \%)$ were replaced in the ASD group and 166 out of 4821 (3.443\%; chi-squared test: $p=.157$ ) in the non-ASD group.

Based on the temporal cluster analysis, the co-occurrence value for each two consecutive words produced by each participant was then allocated to the individual word position as either belonging to a cluster or a switch. For further statistical analysis, the mean co-occurrence value within and outside of clusters was computed per person and task condition.

\section{Orthographic Relatedness}

All tasks were evaluated regarding orthographic relatedness. In individuals without ASD, orthographic relatedness has been shown to facilitate lexical retrieval in word recognition (e.g. Chéreau et al. 2007; Welcome and Trammel 2017) and production (e.g. Lupker 1982; Starreveld and La Heij 1996). Orthographic relatedness is typically assessed by the Levenshtein distance (Levenshtein 1966; Yarkoni et al. 2008) defining 'distance' by the number of letter alterations (i.e. insertions, deletions, or substitutions) needed to transform one word into another (e.g. transformation from 'rope' to 'rules': substitution of 'o' by ' $u$ ' + substitution of 'p' by 'l' + insertion of 's' equals a Levenshtein distance of 3). Lower values of the dimensionless parameter thus indicate a stronger orthographic relatedness. In the current study, Levenshtein distances were computed between each two consecutive words to assess orthographic relatedness per condition and participant (please refer to the Appendix for the computation of the Levenshtein distance). For further statistical analysis, the mean Levenshtein distances within and outside of clusters was computed per person and task condition in a parallel manner as described above for semantic relatedness.

\section{Semantic Content}

We assessed the semantic content of the task conditions 'human features' and 'verbs'. Human features were categorised according to the six semantic main-classes suggested by Baumann et al. (2018) (see Appendix Table 5). Special interest lay in the differentiation between adjectives describing 'external features' (e.g. 'colour', 'sensory characteristics') and 'human dispositions/feelings' (including 'physical feeling', 'behaviour', 'mental state'). Acquisition of the latter follows that of more concrete external features during childhood and is thought to be related to the development of a theory of mind (Baumann et al. 2018). We therefore summarised Baumann's first four main-classes (i.e. age, 'colour', 'judgments', and 'sensory characteristics') as 'external features' and maintained the fifth (i.e. 'human dispositions/feelings') as well as the unspecific sixth (i.e. 'other') main-class.

The semantic analysis of the 'verbs' condition served to assess the production of movement and non-movement related action words. In general, most verbs are defined as action verbs, except for auxiliary, modal, and copula verbs. A variety of systems have proposed a sub-classification of action verbs by their semantic content, commonly dividing them into 'mental actions' (e.g. 'thinking', 'feeling', and 'sensing') and 'physical actions' with a sub-sub-classification into 'intentional physical actions', 'non-intentional processes', and 'states' (Bär 2015; Hentschel and Weydt 2013; Stanford NLP Group 2019) (see Appendix Table 6). On this basis, we differentiated between 'intentional physical actions', 'inactive states' (i.e. sum of 'non-intentional processes' and 'states'), 'mental actions', and 'non-action verbs' (i.e. sum of auxiliary, modal, and copula verbs) for further group comparisons. Absolute values were used for all analyses of semantic content.

\section{Results}

\section{Speech Velocity}

Word length did not differ significantly between the two groups (ASD: $.954 \pm .493 \mathrm{~s}$; non-ASD: $.869 \pm .119 \mathrm{~s}$; $p=.432 ; F_{1,43}=3.039$; Cohen's $d=.239$ ). No subject outliers were detected. 


\section{Verbal Fluency Performance}

\section{Semantic Fluency}

The five LMMs performed to assess VF performance across the three semantic task conditions suggested a lower total number of words, smaller cluster sizes, and longer switch durations among individuals with ASD compared to the non-ASD group. Effect size of group was moderate for cluster size and small for total number of words and switch duration. However, none of the $p$ values, reached the adjusted level of significance (see Table 2A). No group differences were indicated regarding intracluster time and number of switches.

Regarding effects of task condition across both groups, the highest number of words and switches together with shortest intracluster times and switch durations was found in the condition 'animals', followed by 'verbs' and 'human features'. Except for cluster size all $p$ values reached the adjusted level of significance with moderate to large effect sizes (see Appendix Table 7). The models suggested no significant interactions between group and task condition (see Appendix Table Table 8). Despite generally large effect sizes of age, no significant effects of the covariates were indicated (see Appendix Table 9).
Pearson's correlation suggested a tendency towards a weak negative relationship between $A Q$ and the total number of words in the ASD group without reaching the level of significance (ASD: $r=-.335, p=.065$; non-ASD: $r=-.181$, $p=.298$ ) and no significant relationship between $A Q$ and cluster size (ASD: $r=-.202, p=.276$; non-ASD: $r=-.045$, $p=.798$ ) or switch duration (ASD: $r=.107, p=.568$; nonASD: $r=-.067, p=.702$ ).

\section{Letter Fluency}

Regarding the letter fluency task, the LMMs suggested no significant effects of group on the same measures as above along with very low effect sizes (see Table 2B).

The models suggested no significant effects of the covariates on the dependent variables (see Appendix Table 10).

\section{Semantic Relatedness}

\section{Semantic Fluency}

The LMM including all three semantic task conditions to analyse semantic relatedness suggested no significant effect of group along with a very small effect size (ASD: $.154 \pm .086 ;$ non-ASD: $.159 \pm .091 ; p=.335 ; F_{1,411}=.932$; Cohen's $d=.056$ ).
Table 2 Verbal fluency performance: the tables show verbal fluency performance as mean values and standard deviations (SD) of in (A) the three semantic fluency task conditions and (B) the letter fluency task condition in participants with Autism Spectrum Disorder (ASD) and without (non-ASD)

\begin{tabular}{|c|c|c|c|c|c|c|c|}
\hline \multicolumn{8}{|l|}{ (A) Semantic tasks } \\
\hline & \multicolumn{2}{|l|}{ ASD } & \multicolumn{2}{|c|}{ Non-ASD } & \multirow[t]{2}{*}{$p$ value } & \multirow[t]{2}{*}{$F_{1,207}$} & \multirow[t]{2}{*}{ Cohen's $d$} \\
\hline & Mean & SD & Mean & SD & & & \\
\hline Total number of words & 31.021 & 9.504 & 34.607 & 7.808 & .015 & 6.011 & .412 \\
\hline Intracluster time (s) & 2.400 & 1.140 & 2.160 & 686 & .389 & .744 & -.256 \\
\hline Cluster size (words) & 3.481 & .568 & 3.772 & .526 & .007 & 7.476 & .532 \\
\hline Number of switches & 11.281 & 3.395 & 12.051 & 2.962 & .189 & 1.736 & .242 \\
\hline Switch duration (s) & 6.815 & 2.166 & 6.045 & 1.344 & .039 & 4.331 & -.427 \\
\hline \multicolumn{8}{|l|}{ (B) Letter fluency } \\
\hline & \multicolumn{2}{|l|}{ ASD } & \multicolumn{2}{|c|}{ Non-ASD } & \multirow[t]{2}{*}{$p$ value } & \multirow[t]{2}{*}{$F_{1,67}$} & \multirow[t]{2}{*}{ Cohen's $d$} \\
\hline & Mean & SD & Mean & $\mathrm{SD}$ & & & \\
\hline Total number of words & 19.563 & 7.094 & 19.795 & 5.850 & .598 & .281 & .036 \\
\hline Intracluster time (s) & 4.082 & 1.710 & 3.924 & 1.885 & .606 & .268 & -.088 \\
\hline Cluster size (words) & 3.712 & 1.900 & 3.567 & 1.011 & .790 & .072 & -.095 \\
\hline Number of switches & 6.875 & 3.210 & 6.897 & 2.521 & .768 & .088 & .008 \\
\hline Switch duration (s) & 9.542 & 4.586 & 9.726 & 4.574 & .884 & .022 & .040 \\
\hline
\end{tabular}

All group comparisons were computed using linear mixed models (adjusted level of significance $p<.003$ ) 
The model suggested a significant effect of word position within vs. outside of clusters with higher relatedness within than outside of clusters with a $p$ value below the adjusted level of significance and a large effect size (within cluster: $.201 \pm .087$; outside cluster: $.113 \pm .066 ; p<.001$; $F_{1,411}=336.743$; Cohen's $d=-1.140$ ) across both groups (interactions between group and word position within vs. outside of clusters: $p=.325 ; F_{1,411}=.970$ ). Also the effect of task condition appeared significant with highest relatedness between 'animals' and lowest between 'verbs' with a $p$ value below the adjusted level of significance and a large effect size ('animals': .241 \pm .082 ; 'human features': . $119 \pm .061$; 'verbs': $.110 \pm .050 ; p<.001 ; F_{2,411}=314.318 ; \eta^{2}=.453$ ) across both groups (interactions between group and task condition: $\left.p=.409 ; F_{2,411}=.897\right)$. The model furthermore suggested a significant interaction between word position within vs. outside of clusters and 'task conditions' $(p<.001$; $F_{2,411}=8.490$ ) across both groups (see Fig. 2). Effects of the covariates were not suggested to be significant (age: $p=.503 ; \eta^{2}=.344 ; F_{1,411}=.450 ;$ sex $: p=.766 ; F_{1,411}=.089$; $\left.\eta^{2}=.002\right)$.

\section{Letter Fluency}

With respect to letter fluency, semantic relatedness was comparably low with high standard deviations. Values were almost identical in both participant groups (ASD: $.030 \pm .032$; non-ASD: $.030 \pm .037 ; p=.923 ; F_{1,136}=.009$; Cohen's $d<.001)$. Relatedness was slightly higher within than outside of clusters (within cluster: $.038 \pm .036$; outside cluster: $.022 \pm .032 ; p=.010 ; F_{1,136}=6.853$; Cohen's $d=-.470$ ) without reaching the adjusted level of significance. The LMM suggested no significant interaction between the factors group and word position within vs. outside of clusters $\left(p=.239 ; F_{1,136}=1.396\right)$ and no significant effects of the covariates (age: $p=.795 ; F_{1,136}=.068$; $\left.\eta^{2}=.167 ; \operatorname{sex}: p=.470 ; F_{1,136}=.524 ; \eta^{2}=.007\right)$.

\section{Orthographic Relatedness}

\section{Semantic Fluency}

The LMM including all three semantic task conditions to analyse orthographic relatedness suggested no significant effect of group along with a very small effect size (Levenshtein distance ASD: $6.652 \pm 1.420$; non-ASD: $6.576 \pm 1.340 ; p=.393 ; F_{1,409}=.731 ;$ Cohen's $d=-.055$ ). It suggested a significant, moderate effect of word position within vs. outside of clusters with higher relatedness within than outside of clusters (Levenshtein distance within cluster: $6.281 \pm 1.251$; outside cluster: $6.938 \pm 1.470 ; p=<.001$; $F_{1,409}=65.518$; Cohen's $d=.481$ ) across both groups (interactions between group and word position within vs. outside of clusters: $p=.150 ; F_{1,409}=2.082$ ). The model suggested a large effect of task condition with highest relatedness between 'verbs' and lowest between 'human features' (Levenshtein distance 'verbs': $5.343 \pm .698$; 'animals': $6.497 \pm .767$; 'human features': $8.019 \pm 1.118 ; p<.001$, $F_{2,409}=384.175 ; \eta^{2}=.609$ ) across both groups (interactions between group and task condition: $p=.277 ; F_{2,409}=1.288$ ). Lastly, the LMM suggested a small effect of sex across both groups and all three task conditions (Levenshtein distance female: $6.634 \pm 1.284$; male: $6.448 \pm 1.251 ; p=.014$; $F_{1,409}=6.109 ; \eta^{2}=.032$ ), which did not reach the adjusted
Fig. 2 Semantic Relatedness. Regarding semantic relatedness across the three semantic task, there were highly significant effects of task condition (i.e. 'animals', 'features', 'verbs') and word position within vs. outside of clusters as well as an interaction between these two factors (each $\mathrm{p}<.001$ ) but no differences between participant groups. Values are displayed as mean values from both participant groups for each of the three semantic tasks. The ordinate indicates semantic relatedness (ranging from 0 to 1 )
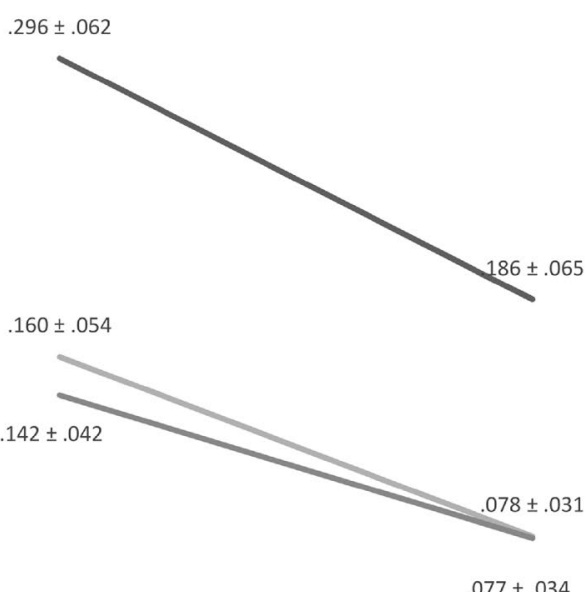

Animals Features Verbs 
level of significance. No significant effect of age was suggested $\left(p=.488 ; F_{1,409}=.482 ; \eta^{2}=.341\right)$.

\section{Letter Fluency}

Regarding the letter fluency task, the LMM suggested that orthographic relatedness did not differ significantly between the groups (Levenshtein distance ASD: $5.578 \pm 1.357$; non-ASD: $5.650 \pm 1.312 ; p=.759 ; F_{1,136}=.094$; Cohen's $d=.054$ ) but within vs. outside of clusters (Levenshtein distance within cluster: $5.269 \pm 1.186$; outside cluster: $5.966 \pm 1.379 ; p=.002 ; \mathrm{F}_{1,136}=10.175 ;$ Cohen's $d=.543$ ). The model indicated no significant interactions between group and word position within vs. outside of clusters $\left(p=.898 ; F_{1,136}=.016\right)$ and no significant effects of age $\left(p=.686 ; F_{1,136}=.164 ; \eta^{2}=.376\right)$ or $\operatorname{sex}(p=.640$; $\left.F_{1,136}=.219 ; \eta^{2}=.003\right)$.

\section{Semantic Content}

The LMM assessing the semantic content of the 'human features' condition suggested no significant effect of group $\left(p=.201 ; F_{1,214}=1.584\right.$; Cohen's $\left.d=.125\right)$ but a significant and large effect of semantic category ('human dispositions/feelings': $16.417 \pm 9.110$ words; 'external features': $7.306 \pm 6.324$ words; 'other': $1.222 \pm 1.606$ words; $\left.p<.001, F_{2,100}=21.709 ; \eta^{2}=.541\right)$ without a significant interaction between group and semantic category $(p=.439$; $F_{2,214}=.827$ ).

With respect to the semantic content of the 'verbs' condition, the LMM suggested no significant effect of group ( $p=.204 ; F_{1,141}=1.626$; Cohen's $\left.d=.159\right)$ but a significant and large effect of semantic category $(p<.001$, $F_{3,274}=421.695 ; \eta^{2}=.818$ ). The model suggested an interaction between group and semantic category $(p=.022$; $F_{3,274}=3.246$ ), however not reaching the adjusted level of significance. Post-hoc t-tests showed a tendency towards fewer 'intentional physical actions' in the ASD vs. non-ASD group (see Table 3), without reaching the adjusted level of significance.

\section{Error Rates}

Kruskal-Wallis analyses suggested no group differences in error rates, although large standard deviations in some conditions may have obscured effects (see Table 4). Specifically, in the condition, 'human features', the error rate was more than three times as high in ASD compared to non-ASD.

\section{Discussion}

The current study explored semantic and letter fluency in individuals with ASD without intellectual impairment in an attempt to characterise underlying lexical network

Table 3 Semantic content, verbs: given a significant interaction between group and semantic category of verbs, post-hoc tests were performed to assess content specific group differences regarding the semantic content of verbs (Mann-Whitney-test for 'non-action verbs', otherwise $t$ tests)

\begin{tabular}{|c|c|c|c|c|c|c|c|}
\hline & \multicolumn{2}{|l|}{ ASD } & \multicolumn{2}{|c|}{ Non-ASD } & \multirow[t]{2}{*}{$p$ value } & \multirow[t]{2}{*}{$F_{1,69}$} & \multirow[t]{2}{*}{ Cohen's $d$} \\
\hline & Mean & SD & Mean & SD & & & \\
\hline Intentional physical actions & 22.344 & 7.677 & 25.667 & 6.768 & .057 & 3.753 & .459 \\
\hline Inactive states & 5.969 & 4.139 & 5.590 & 2.603 & .64 & .221 & -.110 \\
\hline Mental actions & 5.344 & 3.298 & 4.795 & 3.088 & .472 & .522 & -.172 \\
\hline Non-action verbs & 0.188 & 0.64 & 0.128 & 0.409 & .955 & n.a. & -.111 \\
\hline
\end{tabular}

n.a. not applicable

No significant group effects were found. Values are given as absolute number of words produced per semantic category

Table 4 Errors: the total number of errors is given as percentage of the total number of words per task condition and group

\begin{tabular}{|c|c|c|c|c|c|c|}
\hline \multirow[t]{2}{*}{ Errors, total (\%) } & \multicolumn{2}{|l|}{ ASD } & \multicolumn{2}{|c|}{ Non-ASD } & \multirow[t]{2}{*}{$p$ value } & \multirow[t]{2}{*}{$\eta^{2}$} \\
\hline & Mean & $S D$ & Mean & $S D$ & & \\
\hline \multicolumn{7}{|l|}{ Semantic } \\
\hline Animals & 5.548 & 7.188 & 3.809 & 3.506 & .791 & .025 \\
\hline Features & 7.732 & 17.788 & 3.997 & 5.213 & .459 & .022 \\
\hline Verbs & 2.483 & 4.146 & 2.335 & 4.733 & .751 & $<.001$ \\
\hline \multicolumn{7}{|l|}{ Letter } \\
\hline r-Words & 5.408 & 7.030 & 4.453 & 5.696 & .537 & .006 \\
\hline
\end{tabular}

Group comparisons were performed by Kruskal-Wallis analyses 
organisation. Therefore, the primary focus was on differences between the ASD and non-ASD group regarding VF performance, semantic and orthographic relatedness as well as content specific group differences. Analyses of the single VF parameters suggested moderately smaller clusters among individuals with ASD compared to non-ASD along with slightly longer switches and hence a slightly lower number of words in all three semantic task conditions. However, none of these group differences reached the level of significance if corrected for multiple comparisons. There appeared to be no substantial group difference regarding intracluster time or the number of switches. Conversely, in the letter fluency condition, our analyses suggested no relevant group differences regarding clusters, switches, or overall performance. With respect to semantic and orthographic relatedness between consecutive words, no group differences were identified. Yet, both semantic and orthographic relatedness appeared to be significantly stronger within clusters compared to switches. Content analyses of the 'human features' and 'verbs' condition indicated no group-specific differences in the production of socio-emotional or motor action related words. There was no indication of group differences in error rates.

However, comparably small effect sizes of group for each variable point towards a low statistical power so that possible group differences may not have been identified. Application of multiple LMM and the respective adjustment of the level of significance furthermore increased the probability of Type II errors. Therefore, effects which were indicated as significant at the uncorrected level of significance could still be of potential interest and shall therefore be discussed in the theoretical framework of the lexical network, executive functions, and content specific performance.

\section{Lexical Network}

Smaller clusters leading to a lower overall word production only in the semantic task conditions appeared to constitute the most relevant difference between the ASD group and non-ASD in the current study. Reduced word production in semantic fluency tasks among individuals with ASD without intellectual impairment has been described in two earlier studies indicating either pronounced deficits in semantic vs. letter fluency task conditions (Spek et al. 2009) or deficits exclusively in semantic tasks (Inokuchi and Kamio 2013). However, the same authors reported no group differences regarding clusters and switches. Reduced overall word production was also reported by Turner (1999), who furthermore found smaller semantic clusters in both semantic and letter fluency tasks in individuals with ASD compared to non-ASD. This was interpreted as a limited capacity of individuals with ASD to profit from semantic and phonemic relatedness (Turner 1999). Due to basic methodological differences between the use of predefined semantic clusters in the above studies and temporal clusters in the current one, comparability is limited. However, in contrast to Turner (1999) the present findings provided no indication of group differences regarding the use of semantic or phonemic relatedness.

In the framework of the proposed network model, comparably small clusters among individuals with ASD could be indicative of a relatively small scope of closely associated words within the semantic network. Concurrently, in the present study, intracluster time and the estimate of semantic relatedness were largely similar in both groups and thus indicative of similar strength and typicality of established semantic associations. This interpretation appears consistent with two predictions of the WCC theory (Happé and Frith 2006): Firstly, subordination of single items to a higher order category seemed particularly vulnerable to the proposed bias towards detail-focussed processing. Secondly, lower level integration of featural aspects appeared largely unaffected.

WCC has been closely linked to functional hypconnecticvity of neural networks in ASD (Just et al. 2004). Regarding the language network, reduced functional and structural connectivity of various language areas has been associated with differences in language production (Knaus et al. 2010; Verly et al. 2014), comprehension (Goch et al. 2013; Just et al. 2004), and language development (Catani et al. 2016; Naigles et al. 2017) in ASD. A smaller number of closely connected words could thus be rooted in weak connections within areas binding semantic information. In this regard, a particular role for the connection of featural aspects to achieve higher-order generalization (Patterson et al. 2007) and for semantically-driven spoken word production (Mirman et al. 2015) has been ascribed to the anterior temporal lobe. It would therefore appear intriguing to relate behavioural data from temporal cluster analysis to connectivity measures of language specific sub-systems to challenge the here proposed interpretations.

The current study did not include an analysis of typicality or word frequency effects. This appears important to mention because typicality effects could have group-specific effects on VF measures. Word typicality refers to the observation that particular items which appear representative for a given category or share a high number of features with related items are more likely to be produced by a speaker (Rosch and Mervis 1975). Theoretical considerations (Murphy and Medin 1985) and empirical studies embracing, e.g. individual expertise (Bailenson et al. 2002) and socio-cultural background (Burnett et al. 2005) have highlighted that apart from item-inherent features, the speakers' individual experiences and mindsets shape and organise their mental concepts. Considering the high prevalence (Klin et al. 2007) and the intensity (Anthony et al. 2013) of circumscribed interests among children with ASD without intellectual impairment, 
relevant differences in the organisation of mental concepts appear plausible. Moreover, differences in categorisation in early childhood have been proposed to contribute, e.g. to difficulties in social cognition and communication in individuals with ASD (Gastgeb et al. 2006). Gastgeb et al. (2006) showed specifically slower reactions to atypical exemplars of a category among individuals with ASD without intellectual impairment compared to non-ASD (Gastgeb et al. 2006). The authors argued that a bias towards feature-based rather than a holistic processing could entail slower access to the semantic information needed for the categorisation of atypical exemplars. In reverse, slower semantic access to atypical items could have caused smaller temporal clusters in the ASD group of the present study. Assessing groupspecific typicality effects as well as corpus-based estimates of words frequencies could therefore be of value in future studies to characterise in how far personal learning histories shape individual semantic categories.

Of note, Turner (1999) reported even smaller clusters among participants with learning disability (both ASD and non-ASD) than among individuals with ASD without intellectual impairment. This could be interpreted in a way that in addition to ASD-specific effects on cluster size, differences in individual learning skills can also affect cluster formation in diverse participant groups.

As to letter fluency, our present results suggested no group differences in clustering, switching, or overall performance. Although the absence of group differences in this study might be due to low power, this could be in line with the presumption that detail-focussed processing may support orthographic word access strategies in ASD. In a similar sense, studies on reading skills (Nation et al. 2006) and lexical processing (Ferman and Bar-On 2017; Huemer and Mann 2010; Saldaña et al. 2009) in school children and adolescents with ASD have indicated a marked heterogeneity of reading ability with a typical discrepancy between impaired comprehension from semantic context and relatively good orthographical decoding (Huemer and Mann 2010; Nation 1999; Saldaña et al. 2009). These findings seem to corroborate a pattern of intact procedural orthographic abilities but comparably low comprehension skills described in adults with ASD without intellectual impairment (Minshew et al. 1994) and have been associated with difficulties integrating information in context (Huemer and Mann 2010; Nation 1999) as postulated by the WCC theory (Frith 1989). The way in which orthographic processing is involved in lexical decoding and word production is, however, still a matter of debate (Lupker 1982; Starreveld and La Heij 1996; Peleg et al. 2016; Seidenberg and McClelland 1989; Alario et al. 2007; Perret and Laganaro 2012): in individuals without ASD, orthographic facilitation has been described in picture-naming tasks (Lupker 1982; Starreveld and La Heij 1996) and direct connections with conceptual, semantic, and phonemic processing stages have been modelled (Peleg et al. 2016; Seidenberg and McClelland 1989) as well as refuted (Alario et al. 2007; Perret and Laganaro 2012) by experimental word production studies. The current findings may thus indicate a relative advantage in orthographic processing compared to semantic processing during verbal fluency tasks. This is in keeping with a predominance of semantic vs. letter fluency deficits in earlier studies (Inokuchi and Kamio 2013; Spek et al. 2009; Turner 1999). However, the assessment of orthographic relatedness in the present study did not indicate a superior use of orthographic strategies in the ASD vs. non-ASD group. On a side note, male participants across both groups showed a tendency towards higher orthographic relatedness in semantic tasks than female participants. Not reaching the adjusted level of significance and considering the small effect size, a higher statistical power could possibly have revealed group differences. It thus remains speculative if orthographic relationship may have served word retrieval specifically in males. But keeping in mind the "extreme male brain theory of autism" (Baron-Cohen 2002), a possible relationship between orthographic access strategies and sex could be of interest in future studies.

\section{Executive Function}

The number of switches did not largely differ between groups. In the context of frontal lesions, fewer switches have been proposed as indicative of impaired set shifting (Reverberi et al. 2006). In view of a proposed impairment in cognitive flexibility in individuals with ASD (Kleinhans et al. 2005; Ozonoff et al. 2007), a reduced number of switches could have been expected. This notion also appears supported by a finding by Turner (1999) who showed an impaired ability to generate novel ideas in non-verbal fluency (i.e. ideational and design fluency) among able individuals with ASD without intellectual impairment. The present results, however, do not provide evidence for a corresponding dysfunction. Similarly, Spek et al. (2009) reported no difference in the number of switches. This should, however, not preclude the possibility of enhanced task demands inducing detectable difficulties in cognitive flexibility. In fact, fewer switches and a trend towards larger semantic clusters in the VF task condition 'animals' have been reported in children and adolescents with ASD without intellectual impairment (Begeer et al. 2010). This may have originated from relatively higher task demands for children compared to adults.

That said, we found switches to be slightly longer among participants with ASD compared to participants without ASD (not significant if corrected for multiple comparisons, likely due to low power). This could be interpreted in the sense of a proposed connectivity weakness of frontal areas (Catani et al. 2016; Courchesne and Pierce 2005) involved in accessing the semantic knowledge. 
Furthermore, no group differences were indicated regarding error rates in the present study. Although the absence of this effect could be due to low power, it is in keeping with studies portrayed above reporting normal error rates in participants with ASD without intellectual impairment (Begeer et al. 2014; Dunn et al. 1996; Mottron et al. 2001; Turner 1999). In this context, an effect of IQ on executive function highlighted by Ozonoff et al. (2007) appears relevant, considering that in the present study, groups were matched for VIQ ranges. Lastly, the role of executive functions for VF performance has been challenged by a factor-analytic study determining a main impact of language functions on VF (Whiteside et al. 2016).

\section{Content Specific Performance}

In regard to content related group differences, we assessed semantic subcategories of 'human features' and 'verbs'. Against our hypothesis, groups did not differ with respect to the production of external human features vs. human dispositions/feelings (again, low power may have concealed possible group difference). Considering, a preference for factual knowledge (Klin et al. 2007) and sensory oriented interest areas (Anthony et al. 2013), a bias towards the production of external human features in the ASD group would have appeared feasible. A specific disadvantage in the production of words relating to social cognition had furthermore been proposed by Spek et al. (2009) who reported a particularly low word production in the VF category 'professions' in individuals with ASD without intellectual impairment (Spek et al. 2009). This hypothesis is, however, not supported by the present findings which rather appear in line with other studies describing intact usage of emotional words (Helen Tager-Flusberg and Sullivan 1995) as well as mental state and cognition terms during conversation in individuals with ASD (Bang et al. 2013). Corresponding findings may seem at odds with the typical social communicational difficulties, reports on fewer mental-state references (Begeer et al. 2010; Brown et al. 2012), and a suspected hypoconnectivity within the socio-emotional brain network (Ameis et al. 2011). This gap could, however, be explained by the observation of an unhindered production of, but impaired causal attribution of emotional terms in ASD (Capps et al. 2000; Losh and Capps 2006) and a reduced frequency of using emotional terms with increasing social complexity in ASD (Teh et al. 2018). The current results thus support the notion that socioemotional terms are not specifically underrepresented if addressed independently from complex social situations.

With respect to the 'verbs' condition, we found a tendency towards fewer 'intentional physical actions' in the ASD group compared to non-ASD, which failed to reach statistical significance (possibly due to low power). An attenuation of motor-action verb production in individuals with ASD compared to non-ASD appeared plausible in the context of 'embodied semantics' which conceptualises the importance of sensorimotor engagement for multimodal language processing (e.g. Damasio et al. 1994; Kiefer and Pulvermüller 2012; Pulvermüller 1999). Thus, disorders of the motor system have been discussed as impediments to the processing of motor related language, e.g. verb production (Neininger and Pulvermüller 2001 cf. Aravena et al. 2014). Among individuals with ASD, motor dysfunctions-traditionally described as clumsiness (Asperger 1944)_including problems with posture, smoothness, and coordination (Rinehart et al. 2006) as well as disturbed gait (Jansiewicz et al. 2006; Rinehart et al. 2006), balance, and rhythmicity (Jansiewicz et al. 2006) are robustly found (for a metaanalysis see Fournier et al. 2010). Specific deficits in the VF conditions 'sports' and 'action fluency' reported by Inokuchi and Kamio (2013) seem to support this notion. To further explore embodied semantics and respective impairments in individuals with ASD, a stratification by motor symptoms may be considered in future studies.

\section{Study Design}

From a conceptual point of view, it appears of interest that clusters solely defined by temporal patterning showed stronger semantic and orthographic relatedness than switches across all task conditions. This provides support for the theoretical background assuming strong connections between closely related words (both semantic and orthographic) to enable fast lexical access. To our knowledge, this is the first study combining VF analysis via curve fitting with an evaluation of semantic relatedness based on corpusdriven data. Since the present type of analysis allows for an objective evaluation of VF tasks irrespective of a-priori knowledge about semantic subcategories, it may be of value also for future studies.

\section{Limitations}

Upon including a large number of statistical comparisons, none of the group effects, which were found in single LMMs reached the adjusted level of significance. The main findings therefore have to be interpreted with caution. Another critical point are low effect sizes regarding group effects across all dependent variables. These values suggest that the nonsignificant results are more likely due to low power of the current study and do not necessarily indicate the absence of group effects. Future studies could avoid this by using larger sample sizes. Furthermore, the assessment of only one letter fluency condition as opposed to three semantic conditions must also be critically remarked. This reduced the comparability and led to a large number of statistical comparisons. 


\section{Conclusion}

Adults with ASD without intellectual impairment appeared to produce smaller lexical clusters specifically in semantic fluency tasks compared to non-ASD. At the same time, typicality and strength of semantic associations did not seem to differ between groups. Taken together, the findings appear compatible with the ideas put forward in the WCC theory in that they could reflect a comparably weak subordination of single items to a higher order category, while integration of the single aspects of each item seemed unaffected. Moreover, orthographic retrieval strategies may have compensated for semantic network shortcomings. No indication was given for differences in the production of words conveying socioemotional or motor action related content.

Acknowledgements Open Access funding provided by Projekt DEAL. We would like to thank all participants of this study as well as Carla Eising for her contribution.

Author Contributions FE made substantial contributions to the study's conception and design, data analysis and interpretation, drafted the manuscript, and gave final approval. SR made substantial contributions to the study's conception and design, interpretation of the data, revised the manuscript critically, and gave final approval. FK made substantial contributions to the study's conception and design, revised the manuscript critically, and gave final approval. IB made substantial contributions to data acquisition, revised the manuscript critically, and gave final approval. PG made substantial contributions to data acquisition and analysis, revised the manuscript critically, and gave final approval. CB made substantial contributions to data analysis, revised the manuscript critically, and gave final approval. HOT made substantial contributions to the study's conception and design, revised the manuscript critically, and gave final approval. BB made substantial contributions to the study's conception and design, revised the manuscript critically, and gave final approval.

Funding There was no funding for the current study.

\section{Compliance with Ethical Standards}

Conflict of interest The authors declare that they have no conflict of interest.

Ethical Approval Each participant gave written informed consent to participation in the current study which was approved by the local ethics committee (EA1/392/16) and was conducted in accordance with the Declaration of Helsinki.

Open Access This article is licensed under a Creative Commons Attribution 4.0 International License, which permits use, sharing, adaptation, distribution and reproduction in any medium or format, as long as you give appropriate credit to the original author(s) and the source, provide a link to the Creative Commons licence, and indicate if changes were made. The images or other third party material in this article are included in the article's Creative Commons licence, unless indicated otherwise in a credit line to the material. If material is not included in the article's Creative Commons licence and your intended use is not permitted by statutory regulation or exceeds the permitted use, you will need to obtain permission directly from the copyright holder. To view a copy of this licence, visit http://creativecommons .org/licenses/by/4.0/.

\section{Appendix 1}

See Tables 5, 6, 7, 8, 9, and 10.

Table 5 Words produced in the category 'human features' were categorised semantically as proposed by Baumann et al. (2018; own translation given in the table)

\begin{tabular}{llll}
\hline & Main classes & Sub-classes & Example \\
\hline 1 & Age & & Old, new \\
2 & Colour & & Red \\
3 & Appraisal & & Important, bad \\
4_a & Sensory characteristics & Texture & Rough \\
4_b & Shape & Round \\
4_c & Dimension & Large \\
4_d & Consistency & Soft \\
4_e & Functionality & Broken \\
4_f & Purity & Dirty \\
4_g & Sensory impression & Hearty \\
4_h & Velocity & Fast \\
4_i & Temperature & Cold \\
4_j & Appearance & Dark \\
4_k & Palatability & Ripe \\
5_a & Human dispositions/ & Physical feeling & Hungry, sick \\
& feelings & & \\
5_b & Behaviour & Decent, lazy \\
5_c & Mental State & Sad, clever \\
6_a & Other & Conformity & Unfit \\
6_b & Time & Early \\
6_c & Quantity & Rare, rich, full \\
6_d & Other & \\
\hline
\end{tabular}

For further analysis, we summarised the main-classes 1-4 as 'external features' and maintained the main-classes 5 and 6 
Table 6 Categorisation of verbs was conducted based on common classification systems (Bär 2015; Hentschel and Weydt 2013; Stanford NLP Group 2019)

\begin{tabular}{llll}
\hline Category & Main classes & Sub-classes & Example \\
\hline Action verbs & Physical actions & Intentional physical actions $^{\mathrm{a}}$ & $\begin{array}{c}\text { Run, throw, give, beat (usually } \\
\text { used with object) } \\
\text { Fall, grow, die, decay } \\
\text { stand, lie, sit, stay }\end{array}$ \\
& Non-intentional Processes $^{\mathrm{b}}$ & Think, contemplate \\
& States $^{\mathrm{b}}$ & Thinking $^{\mathrm{c}}$ & Like, hate, want, need \\
Non-action verbs & Wanting $^{\mathrm{c}}$ & Sensing $^{\mathrm{c}}$ & See, smell, hear, taste \\
& & & Have, be, appear, seem, smell, taste \\
& Copula verbs ${ }^{\mathrm{d}}$ & & Have, be \\
& Auxiliary verbs & Need, may, want, can, must, will \\
\hline
\end{tabular}

For further group comparisons, words were grouped as follows: ' ‘intentional physical actions'; ' ‘'inactive states'; ‘'mental actions'; d‘non-action verbs'

Table 7 Linear mixed models suggested significant effects of task condition for the three semantic task conditions (i.e. 'animals', 'human features', 'verbs') regarding verbal fluency parameters

\begin{tabular}{|c|c|c|c|c|c|c|c|c|c|}
\hline & \multicolumn{2}{|c|}{ Animals } & \multicolumn{2}{|c|}{ Features } & \multicolumn{2}{|l|}{ Verbs } & \multirow[t]{2}{*}{$p$ value } & \multirow[t]{2}{*}{$F_{2,207}$} & \multirow[t]{2}{*}{$\eta^{2}$} \\
\hline & Mean & SD & Mean & SD & Mean & SD & & & \\
\hline Total number of words & 37.099 & 9.846 & 26.620 & 9.607 & 35.254 & 10.410 & $<.001$ & 22.562 & .176 \\
\hline Intracluster time (s) & 1.901 & 1.152 & 2.757 & 1.558 & 2.096 & .645 & $<.001$ & 9.666 & .080 \\
\hline Cluster size (words) & 3.711 & .627 & 3.446 & .907 & 3.766 & .824 & .036 & 3.370 & .030 \\
\hline Number of switches & 13.070 & 3.603 & 9.451 & 3.949 & 12.592 & 4.251 & $<.001$ & 17.917 & .144 \\
\hline Switch duration (s) & 5.672 & 1.685 & 7.658 & 2.793 & 5.827 & 2.021 & $<.001$ & 15.200 & .125 \\
\hline
\end{tabular}

Generally, the largest number of words along with shortest intracluster times, most switches and shortest switch duration was found in the category 'animals' followed by 'verbs', and lastly 'human features'

Table 8 Linear mixed models performed to assess VF performance parameters across all three semantic task conditions and both participant groups indicated no significant interactions between group and task condition

\begin{tabular}{llr}
\hline Interaction group $*$ task condition & $p$ & $F_{2,205}$ \\
\hline Total number of words & .733 & .311 \\
Intracluster time (s) & .541 & .616 \\
Cluster size (words) & .361 & 1.025 \\
Number of switches & .791 & .235 \\
Switch duration (s) & .749 & .289 \\
\hline
\end{tabular}

Table 9 Across all three semantic task conditions and both participant groups, linear mixed models indicated no significant effects of the covariates age and sex, although effect sizes of age were generally large

\begin{tabular}{|c|c|c|c|c|c|c|}
\hline & \multicolumn{3}{|l|}{ Age } & \multicolumn{3}{|l|}{ Sex } \\
\hline & $p$ & $F_{1,205}$ & $\eta^{2}$ & $p$ & $F_{1,205}$ & $\eta^{2}$ \\
\hline Total number of words & .082 & 3.058 & .352 & .733 & .117 & $<.001$ \\
\hline Intracluster time (s) & .176 & 1.846 & .324 & .823 & .050 & .002 \\
\hline Cluster size (words) & .914 & .012 & .327 & .550 & .359 & .001 \\
\hline Number of switches & .092 & 2.863 & .323 & .403 & .702 & .006 \\
\hline Switch duration (s) & .308 & .775 & .272 & .757 & .096 & .001 \\
\hline
\end{tabular}


Table 10 For the letter fluency condition, linear mixed models indicated no significant effects of the covariates age and sex across both participant groups

\begin{tabular}{|c|c|c|c|c|c|c|}
\hline & \multicolumn{3}{|l|}{ Age } & \multicolumn{3}{|l|}{ Sex } \\
\hline & $p$ & $F_{1,67}$ & $\eta^{2}$ & $p$ & $F_{1,67}$ & $\eta^{2}$ \\
\hline $\begin{array}{l}\text { Total number of } \\
\text { words }\end{array}$ & .086 & 3.038 & .338 & .158 & 2.04 & .019 \\
\hline Intracluster time (s) & .433 & .623 & .214 & .575 & .317 & .002 \\
\hline Cluster size (words) & .734 & .117 & .237 & .167 & 1.951 & .033 \\
\hline Number of switches & .340 & .923 & .317 & .227 & 1.488 & .017 \\
\hline Switch duration (s) & .169 & 1.930 & .282 & .223 & 1.51 & .016 \\
\hline
\end{tabular}

\section{Computation of the Levenshtein Distance}

The Levenshtein distance between two strings $a, b$ (of length $|a|$ and $|b|$ respectively) is given by $\operatorname{lev}_{a, b}(|a|,|b|)$ where

$\operatorname{lev}_{a, b}(i, j)=\left\{\begin{array}{lc}\max (i, j) & \text { if } \min (i, j)=0, \\ \min \left\{\begin{array}{l}\operatorname{lev}_{a, b}(i-1, j)+1 \\ \operatorname{lev}_{a, b}(i, j-1)+1 \\ \operatorname{lev}_{a, b}(i-1, j-1)+1_{\left(a_{i} \neq b_{j}\right)}\end{array}\right. & \text { otherwise. }\end{array}\right.$

where $1_{\left(a_{i} \neq b_{j}\right)}$ is the indicator function equal to 0 when $a_{i}=b_{j}$ and equal to 1 otherwise, and $\operatorname{lev}_{a, b}(i, j)$ is the distance between the first $i$ characters of $a$ and the first $j$ characters of $b . i$ and $j$ are 1-based indices.

To calculate the value of $\operatorname{lev}_{\text {word } 1 \text {,word } 2}$ for each pair of consecutive words [word 1, word2] in the VF tests, we used the following perl implementation of the Levenshtein distance: use List::Util qw(min);

sub $\underline{\text { lev }}\{$

my $($ word1, \$word2 $)=@$;

my@ar1=split //, \$word1;

my@ar2=split //, \$word2;

my@dist;

$\$ \operatorname{dist}[\$][0]=\$ \_$foreach $(0 \ldots @ \operatorname{ar} 1)$

$\$ \operatorname{dist}[0]\left[\$ \_\right]=\$$ foreach $(0$.. @ar2);

foreach my \$i (1..@ar1)

foreach my \$j (1..@@ar2)\{

my $\$ \operatorname{cost}=\$ \operatorname{ar} 1[\$ \mathrm{i}-1]$ eq $\$ \operatorname{ar} 2[\$ \mathrm{j}-1] ? 0: 1$

$\$ \operatorname{dist}[\$ i][\$ j]=\min ($

$\$ \operatorname{dist}[\$ \mathrm{i}-1][\$ \mathrm{j}]+1$,

$\$ \operatorname{dist}[\$ \mathrm{i}][\$ \mathrm{j}-1]+1$,

$\$ \operatorname{dist}[\$ \mathrm{i}-1][\$ \mathrm{j}-1]+\$ \operatorname{cost})$

\} $\}$

return \$dist[@ar1][@ar2];

\}

The calculated values of $\operatorname{lev}_{\text {word1,word2 }}$ were integers between 0 and $\max (|\operatorname{word} 1|, \mid$ word $2 \mid)$ 


\section{References}

Alario, F. X., Perre, L., Castel, C., \& Ziegler, J. C. (2007). The role of orthography in speech production revisited. Cognition. https:// doi.org/10.1016/j.cognition.2006.02.002.

Ameis, S. H., Fan, J., Rockel, C., Voineskos, A. N., Lobaugh, N. J., Soorya, L., ... Anagnostou, E. (2011). Impaired structural connectivity of socio-emotional circuits in autism spectrum disorders: A diffusion tensor imaging study. PLoS ONE. https://doi. org/10.1371/journal.pone.0028044.

American Psychiatric Association. (2013). Diagnostic and statistical manual of mental disorders (5th ed.). Arlington: American Psychiatric Association.

Anthony, L. G., Kenworthy, L., Yerys, B. E., Jankowski, K. F., James, J. D., Harms, M. B., .. Wallace, G. L. (2013). Interests in highfunctioning autism are more intense, interfering, and idiosyncratic than those in neurotypical development. Development and Psychopathology. https://doi.org/10.1017/S0954579413000072.

Aravena, P., Courson, M., Frak, V., Cheylus, A., Paulignan, Y., Deprez, V., et al. (2014). Action relevance in linguistic context drives word-induced motor activity. Frontiers in Human Neuroscience, 8(April), 1-12. https://doi.org/10.3389/fnhum.2014.00163.

Arnold Anteraper, S., D’Mello, A., Joshi, G., Joshi, N., WhitfieldGabrieli, S., \& Guell, X. (2018). Disrupted cerebrocerebellar intrinsic functional connectivity in young adults with high-functioning autism spectrum disorder: A data-driven, whole-brain, high-temporal resolution functional magnetic resonance imaging study. Brain Connectivity, 9(1), 48-59. https://doi.org/10.1089/ brain.2018.0581.

Aschenbrenner, S., \& Tucha Lange, O. (2001). RWT-Regensburger Wortflüssigkeitstest (Part 1). Göttingen: Hogrefe Verlag für Psychologie.

Asperger, H. (1944). Die "Autistischen Psychopathen" im Kindesalter. Archiv Fur Psychiatrie Und Nervenkrankheiten, 117, 76-136.

Bailenson, J. N., Shum, M. S., Atran, S., Medin, D. L., \& Coley, J. D. (2002). A bird's eye view: Biological categorization and reasoning within and across cultures. Cognition. https://doi. org/10.1016/S0010-0277(02)00011-2.

Baio, J., Wiggins, L., Christensen, D. L., Maenner, M. J., Daniels, J., Warren, Z., ... Dowling, N. F. (2018). Prevalence of autism spectrum disorder among children aged 8 years-autism and developmental disabilities monitoring network, 11 sites, United States, 2014. MMWR Surveillance Summaries. https://doi.org/10.15585 /mmwr.ss6706a1

Bang, J., Burns, J., \& Nadig, A. (2013). Brief report: Conveying subjective experience in conversation: Production of mental state terms and personal narratives in individuals with high functioning autism. Journal of Autism and Developmental Disorders, 43(7), 1732-1740. https://doi.org/10.1007/s10803-012-1716-4.

Bär, J. A. (2015). Hermeneutische Linguistik: Theorie und Praxis grammatisch-semantischer Interpretation. Berlin: De Gruyter.

Baron-Cohen, S. (1988). Social and pragmatic deficits in autism: Cognitive or affective? Journal of Autism and Developmental Disorders. https://doi.org/10.1007/BF02212194.

Baron-Cohen, S. (2002). The extreme male brain theory of autism. Trends in Cognitive Sciences. https://doi.org/10.1016/S1364 -6613(02)01904-6.

Baron-Cohen, S., Hoekstra, R. A., Knickmeyer, R., \& Wheelwright, S. (2006). The autism-spectrum quotient (AQ)-adolescent version. Journal of Autism and Developmental Disorders, 36(3), 343-350. https://doi.org/10.1007/s10803-006-0073-6.

Baron-Cohen, S., Leslie, A. M., \& Frith, U. (1985). Does the autistic child have a "theory of mind"? Cognition. https://doi. org/10.1016/0010-0277(85)90022-8.
Baumann, C., Dabóczi, V., \& Hartlmaier, S. (2018). Adjektive: Grammatik, Pragmatik, Erwerb. Berlin: De Gruyter.

Begeer, S., Malle, B. F., Nieuwland, M. S., \& Keysar, B. (2010). Using theory of mind to represent and take part in social interactions: Comparing individuals with high-functioning autism and typically developing controls. European Journal of Developmental Psychology, 7(1), 104-122. https://doi. org/10.1080/17405620903024263.

Begeer, S., Wierda, M., Scheeren, A. M., Teunisse, J. P., Koot, H. M., \& Geurts, H. M. (2014). Verbal fluency in children with autism spectrum disorders: Clustering and switching strategies. Autism, 18(8), 1014-1018. https://doi.org/10.1177/13623 61313500381

Belica, C. (1995). Statistische Kollokationsanalyse und -clustering. Korpuslinguistische Analysemethode. Mannheim: Institut für Deutsche Sprache.

Belica, C. (2001). Kookkurrenzdatenbank CCDB. Eine korpuslinguistische Denk- und Experimentierplattform für die Erforschung und theoretische Begründung von systemisch-strukturellen Eigenschaften von Kohäsionsrelationen zwischen den Konstituenten des Sprachgebrauchs. Mannheim: Institut für Deutsche Sprache. Retrieved from https://corpora.ids-mannheim.de/ccdb/.

Belmonte, M. K. (2004). Autism and Abnormal Development of Brain Connectivity. Journal of Neuroscience. https://doi.org/10.1523/ jneurosci.3340-04.2004.

Binder, J. R., \& Desai, R. H. (2011). The neurobiology of semantic memory. Trends in Cognitive Sciences. https://doi.org/10.1016/j. tics.2011.10.001.

Birn, R. M., Kenworthy, L., Case, L., Caravella, R., Jones, T. B., Bandettini, P. A., et al. (2010). Neural systems supporting lexical search guided by letter and semantic category cues: A self-paced overt response fMRI study of verbal fluency. NeuroImage. https ://doi.org/10.1016/j.neuroimage.2009.07.036.

Bölte, S., \& Poustka, F. (2005). Psychodiagnostic instruments for the assessment of autism spectrum disorders. Zeitschrift Fur Kinder- Und Jugendpsychiatrie Und Psychotherapie. https:// doi.org/10.1024/1422-4917.33.1.5.

Boucher, J. (2003). Language development in autism. International Journal of Pediatric Otorhinolaryngology. https://doi. org/10.1016/j.ijporl.2003.08.016.

Bousfield, W. A., \& Sedgewick, C. H. W. (1944). An analysis of sequences of restricted associative responses. Journal of General Psychology. https://doi.org/10.1080/00221309.1944.10544467.

Brown, B. T., Morris, G., Nida, R. E., \& Baker-Ward, L. (2012). Brief report: Making experience personal: Internal states language in the memory narratives of children with and without Asperger's Disorder. Journal of Autism and Developmental Disorders. https ://doi.org/10.1007/s10803-011-1246-5.

Burnett, R. C., Medin, D. L., Ross, N. O., \& Blok, S. V. (2005). Ideal is typical. Canadian Journal of Experimental Psychology. https ://doi.org/10.1037/h0087453.

Capps, L., Losh, M., \& Thurber, C. (2000). "The frog ate the bug and made his mouth sad": Narrative competence in children with autism. Journal of Abnormal Child Psychology. https://doi. org/10.1023/A:1005126915631.

Catani, M., Dell'Acqua, F., Budisavljevic, S., Howells, H., Thiebaut de Schotten, M., Froudist-Walsh, S., ... Murphy, D. G. (2016). Frontal networks in adults with autism spectrum disorder. Brain: A Journal of Neurology, 139(Pt 2), 616-630. https://doi. org/10.1093/brain/awv351.

Chéreau, C., Gaskell, M. G., \& Dumay, N. (2007). Reading spoken words: Orthographic effects in auditory priming. Cognition. https ://doi.org/10.1016/j.cognition.2006.01.001.

Cho, A, B., Otte, K., Baskow, I., Ehlen, F., Maslahati, T., \& Mansow-Model, S. et al. (2020). Detecting motor function abnormalities in individuals with Autism Spectrum Disorder without 
intellectual impairment via visual-perceptive computing. Pharmacopsychiatry, 53(02), 81.

Cohen, J. (1988a). The analysis of variance and covariance. In Statistical power analysis for the behavioral sciences (2nd ed., pp. 273-407). New York: Lawrence Erlbaum Associates.

Cohen, J. (1988b). The effect size index: d. in Statistical power analysis for the behavioral sciences (2nd ed., pp. 20-27). New York: Lawrence Erlbaum Associates.

Collins, A. M., \& Loftus, E. F. (1975). A spreading-activation theory of semantic processing. Psychological Review. https://doi. org/10.1037/0033-295X.82.6.407.

Courchesne, E., \& Pierce, K. (2005). Why the frontal cortex in autism might be talking only to itself: Local over-connectivity but longdistance disconnection. Current Opinion in Neurobiology. https ://doi.org/10.1016/j.conb.2005.03.001.

Damasio, A. R., Damasio, H., Koch, C., \& Davis, J. L. (1994). Cortical systems for retrieval of concrete knowledge: The convergence zone framework. In Large-scale neuronal theories of the brain.

Dell, G. S. (1986). A spreading-activation theory of retrieval in sentence production. Psychological Review, 93(3), 283-321.

Dunn, M., Gomes, H., \& Sebastian, M. J. (1996). Prototypicality of responses of autistic, language disordered, and normal children in a word fluency task. Child Neuropsychology, 2(2), 99-108. https://doi.org/10.1080/09297049608401355.

Eales, M. J. (1993). Pragmatic impairments in adults with childhood diagnoses of autism or developmental receptive language disorder. Journal of Autism and Developmental Disorders. https://doi. org/10.1007/BF01046104.

Ecker, C., Andrews, D., Dell'Acqua, F., Daly, E., Murphy, C., Catani, M., ... Murphy, D. G. M. (2016). Relationship between cortical gyrification, white matter connectivity, and autism spectrum disorder. Cerebral Cortex, 26(7), 3297-3309. https://doi. org/10.1093/cercor/bhw098.

Ehlen, F., Fromm, O., Vonberg, I., \& Klostermann, F. (2016). Overcoming duality: the fused Bousfieldian function for modeling word production in verbal fluency tasks. Psychonomic Bulletin and Review. https://doi.org/10.3758/s13423-015-0987-0.

Elgamal, S. A., Roy, E. A., \& Sharratt, M. T. (2011). Age and verbal fluency: The mediating effect of speed of processing. Canadian Geriatrics Journal. https://doi.org/10.5770/cgj.v14i3.17.

Ferman, S., \& Bar-On, A. (2017). Morpho-orthographic processing in children with autism spectrum disorder: The case of Hebrew orthography. Folia Phoniatrica et Logopaedica, 69(1-2), 54-66. https://doi.org/10.1159/000479062.

Fine, E. M., Delis, D. C., Paul, B. M., \& Filoteo, J. V. (2011). Reduced verbal fluency for proper names in nondemented patients with Parkinson's disease: A quantitative and qualitative analysis. Journal of Clinical and Experimental Neuropsychology. https://doi. org/10.1080/13803395.2010.507185.

Fournier, K. A., Hass, C. J., Naik, S. K., Lodha, N., \& Cauraugh, J. H. (2010). Motor coordination in autism spectrum disorders: A synthesis and meta-analysis. Journal of Autism and Developmental Disorders, 40(10), 1227-1240. https://doi.org/10.1007/ s10803-010-0981-3.

Frith, U. (1989). Autism: Explaining the enigma. Oxford: Basil Blackwell.

Gastgeb, H. Z., Strauss, M. S., \& Minshew, N. J. (2006). Do individuals with autism process categories differently? The effect of typicality and development. Child Development. https://doi. org/10.1111/j.1467-8624.2006.00969.

Goch, C. J., Stieltjes, B., Henze, R., Hering, J., Meinzer, H. P., \& Fritzsche, K. H. (2013). Quantification of changes in language-related brain areas in autism spectrum disorders using large-scale network analysis. Informatik Aktuell. https://doi. org/10.1007/978-3-642-36480-8_11.
Groen, W. B., Zwiers, M. P., van der Gaag, R. J., \& Buitelaar, J. K. (2008). The phenotype and neural correlates of language in autism: An integrative review. Neuroscience and Biobehavioral Reviews, 32(8), 1416-1425. https://doi.org/10.1016/j.neubi orev.2008.05.008.

Gruenewald, P. J., \& Lockhead, G. R. (1980). The free recall of category examples. Journal of Experimental Psychology: Human Learning and Memory. https://doi. org/10.1037/0278-7393.6.3.225.

Happé, F., \& Frith, U. (2006). The weak coherence account: Detailfocused cognitive style in autism spectrum disorders. Journal of Autism and Developmental Disorders. https://doi.org/10.1007/ s10803-005-0039-0.

Henry, J. D., \& Crawford, J. R. (2005). A meta-analytic review of verbal fluency deficits in depression. Journal of Clinical and Experimental Neuropsychology. https://doi.org/10.1080/13803 3990513654.

Hentschel, E., \& Weydt, H. (2013). Handbuch der deutschen Grammatik von (4th comple). Berlin: De Gruyter.

Hickok, G., \& Poeppel, D. (2004). Dorsal and ventral streams: A framework for understanding aspects of the functional anatomy of language. Cognition. https://doi.org/10.1016/j.cogni tion.2003.10.011.

Hong, S. J., Hyung, B., Paquola, C., \& Bernhardt, B. C. (2019). The superficial white matter in autism and its role in connectivity anomalies and symptom severity. Cerebral Cortex. https://doi. org/10.1093/cercor/bhy321.

Huemer, S. V., \& Mann, V. (2010). A comprehensive profile of decoding and comprehension in autism spectrum disorders. Journal of Autism and Developmental Disorders. https://doi.org/10.1007/ s10803-009-0892-3.

Hull, J. V., Dokovna, L. B., Jacokes, Z. J., Torgerson, C. M., Irimia, A., \& Van Horn, J. D. (2017). Resting-state functional connectivity in autism spectrum disorders: A review. Frontiers in Psychiatry, 7, 205. https://doi.org/10.3389/fpsyt.2016.00205.

Indefrey, P., \& Levelt, W. J. M. (2004). The spatial and temporal signatures of word production components. Cognition. https://doi. org/10.1016/j.cognition.2002.06.001.

Inokuchi, E., \& Kamio, Y. (2013). Qualitative analyses of verbal fluency in adolescents and young adults with high-functioning autism spectrum disorder. Research in Autism Spectrum Disorders. https://doi.org/10.1016/j.rasd.2013.08.010.

Jansiewicz, E. M., Goldberg, M. C., Newschaffer, C. J., Denckla, M. B., Landa, R., \& Mostofsky, S. H. (2006). motor signs distinguish children with high functioning autism and Asperger's syndrome from controls. Journal of Autism and Developmental Disorders. https://doi.org/10.1007/s10803-006-0109-y.

Just, M. A., Cherkassky, V. L., Keller, T. A., \& Minshew, N. J. (2004). Cortical activation and synchronization during sentence comprehension in high-functioning autism: Evidence of underconnectivity. Brain. https://doi.org/10.1093/brain/awh199.

Kiefer, M., \& Pulvermüller, F. (2012). Conceptual representations in mind and brain: Theoretical developments, current evidence and future directions. Cortex, 48(7), 805-825. https://doi. org/10.1016/j.cortex.2011.04.006.

Kjelgaard, M. M., \& Tager-Flusberg, H. (2001). An Investigation of language impairment in autism: Implications for genetic subgroups. Language and Cognitive Processes. https://doi. org/10.1080/01690960042000058.

Kleinhans, N., Akshoomoff, N., \& Delis, D. C. (2005). Executive functions in autism and Asperger's disorder: flexibility, fluency, and inhibition. Developmental Neuropsychology, 27(3), 379-401. https://doi.org/10.1207/s15326942dn2703_5.

Klin, A., Danovitch, J. H., Merz, A. B., \& Volkmar, F. R. (2007). Circumscribed interests in higher functioning individuals with autism spectrum disorders: An exploratory study. Research 
and Practice for Persons with Severe Disabilities. https://doi. org/10.2511/rpsd.32.2.89.

Knaus, T. A., Silver, A. M., Kennedy, M., Lindgren, K. A., Dominick, K. C., Siegel, J., et al. (2010). Language laterality in autism spectrum disorder and typical controls: A functional, volumetric, and diffusion tensor MRI study. Brain and language, 112(2), 113-120. https://doi.org/10.1016/j.bandl.2009.11.005.

Labache, L., Joliot, M., Saracco, J., Jobard, G., Hesling, I., Zago, L., ... Tzourio-Mazoyer, N. (2019). A SENtence Supramodal Areas AtlaS (SENSAAS) based on multiple task-induced activation mapping and graph analysis of intrinsic connectivity in 144 healthy right-handers. Brain Structure and Function. https://doi. org/10.1007/s00429-018-1810-2.

Levelt, W. J. M. (1999). Models of word production. Trends in Cognitive Sciences. https://doi.org/10.1016/S1364-6613(99)01319-4.

Levenshtein, V. (1966). Binary codes capable of correcting deletions, insertions, and reversals. Soviet Physics Doklady.

Lord, C., Rutter, M., Goode, S., Heemsbergen, J., Jordan, H., Mawhood, L., et al. (1989). Austism diagnostic observation schedule: A standardized observation of communicative and social behavior. Journal of Autism and Developmental Disorders. https://doi. org/10.1007/BF02211841.

Lord, C., Rutter, M., \& Le Couteur, A. (1994). Autism diagnostic interview-revised: A revised version of a diagnostic interview for caregivers of individuals with possible pervasive developmental disorders. Journal of Autism and Developmental Disorders. https ://doi.org/10.1007/BF02172145.

Losh, M., \& Capps, L. (2006). Understanding of emotional experience in autism: Insights from the personal accounts of high-functioning children with autism. Developmental Psychology. https://doi. org/10.1037/0012-1649.42.5.809.

Lüdecke, D. (2017). Effect size statistics for Anova tables \#rstats. Retrieved June 28, 2019, from https://strengejacke.wordpress. com/2017/07/25/effect-size-statistics-for-anova-tables-rstats/.

Lupker, S. J. (1982). The role of phonetic and orthographic similarity in picture-word interference. Canadian Journal of Psychology. https://doi.org/10.1037/h0080652.

Martin, I., \& McDonald, S. (2003). Weak coherence, no theory of mind, or executive dysfunction? Solving the puzzle of pragmatic language disorders. Brain and Language, 85(3), 451-466. https ://doi.org/10.1016/S0093-934X(03)00070-1.

Masi, A., DeMayo, M. M., Glozier, N., \& Guastella, A. J. (2017). An Overview of autism spectrum disorder, heterogeneity and treatment options. Neuroscience Bulletin. https://doi.org/10.1007/ s12264-017-0100-y.

Murphy, G. L., \& Medin, D. L. (1985). The role of theories in conceptual coherence. Psychological Review. https://doi. org/10.1037/0033-295X.92.3.289.

Minshew, N. J., Goldstein, G., Taylor, H. G., \& Siegel, D. J. (1994). academic achievement in high functioning autistic individuals. Journal of Clinical and Experimental Neuropsychology, 16(2), 261-270. https://doi.org/10.1080/01688639408402637.

Mirman, D., Chen, Q., Zhang, Y., Wang, Z., Faseyitan, O. K., Coslett, H. B., et al. (2015). Neural organization of spoken language revealed by lesion-symptom mapping. Nature Communications. https://doi.org/10.1038/ncomms7762.

Mottron, L., Morasse, K., \& Belleville, S. (2001). A study of memory functioning in individuals with autism. Journal of Child Psychology and Psychiatry and Allied Disciplines, 42(2), 253-260. https ://doi.org/10.1017/S0021963001006722.

Naigles, L. R., Johnson, R., Mastergeorge, A., Ozonoff, S., Rogers, S. J., Amaral, D. G., \& Nordahl, C. W. (2017). Neural correlates of language variability in preschool-aged boys with autism spectrum disorder. Autism Research, 10(6), 1107-1119. https://doi. org/10.1002/aur.1756.
Nakagawa, S. (2004). A farewell to Bonferroni: The problems of low statistical power and publication bias. Behavioral Ecology. https ://doi.org/10.1093/beheco/arh107.

Nation, K. (1999). Reading skills in hyperlexia: A developmental perspective. Psychological Bulletin, 125(3), 338-355. https://doi. org/10.1037/0033-2909.125.3.338.

Nation, K., Clarke, P., Wright, B., \& Williams, C. (2006). Patterns of reading ability in children with autism spectrum disorder. Journal of Autism and Developmental Disorders, 36(7), 911-919. https://doi.org/10.1007/s10803-006-0130-1.

Neininger, B., \& Pulvermüller, F. (2001). The right hemisphere's role in action word processing: A double case study. Neurocase, 7(4), 303-317. https://doi.org/10.1093/neucas/7.4.303.

Ozonoff, S. (1997). Components of executive fucntion in autism and other disorders. In J. Russell (Ed.), Autism as an executive disorder. Oxford: Oxford University Press.

Ozonoff, S., South, M., \& Provencal, S. (2007). Executive functions in autism: Theory and practice. In Pérez, J. M., Gonzalez, P. M., Comi, M. L., Nieto, C. (Eds), New developments in Autism; the future is today. London, England: Jessica Kingsley.

Patterson, K., Nestor, P. J., \& Rogers, T. T. (2007). Where do you know what you know? The representation of semantic knowledge in the human brain. Nature Reviews Neuroscience. https://doi. org/10.1038/nrn2277.

Peleg, O., Edelist, L., Eviatar, Z., \& Bergerbest, D. (2016). Lexical factors in conceptual processes: The relationship between semantic representations and their corresponding phonological and orthographic lexical forms. Memory and Cognition, 44(4), 519-537. https://doi.org/10.3758/s13421-015-0576-5.

Perret, C., \& Laganaro, M. (2012). Comparison of electrophysiological correlates of writing and speaking: A topographic ERP analysis. Brain Topography, 25(1), 64-72. https://doi.org/10.1007/s1054 8-011-0200-3.

Premack, D., \& Woodruff, G. (1978). Does the chimpanzee have a theory of mind? Behavioral and Brain Sciences. https://doi. org/10.1017/S0140525X00076512.

Pulvermüller, F. (1999). Words in the brain's language. Behavioral and Brain Sciences. https://doi.org/10.1017/S0140525X9900182X.

Reverberi, C., Laiacona, M., \& Capitani, E. (2006). Qualitative features of semantic fluency performance in mesial and lateral frontal patients. Neuropsychologia, 44(3), 469-478. https://doi. org/10.1016/j.neuropsychologia.2005.05.011.

Rinehart, N. J., Tonge, B. J., Bradshaw, J. L., \& Enticott, P. G. (2006). Gait function in high-functioning autism and Asperger' $\mathrm{s}$ disorder. European Child \& Adolescent Psychiatry. https://doi. org/10.1007/s00787-006-0530-y.

Robinson, G., Shallice, T., Bozzali, M., \& Cipolotti, L. (2012). The differing roles of the frontal cortex in fluency tests. Brain. https ://doi.org/10.1093/brain/aws142.

Roelofs, A. (1992). A spreading-activation theory of lemma retrieval in speaking. Cognition. https://doi.org/10.1016/00100277(92)90041-F.

Roelofs, A., Meyer, A. S., \& Levelt, W. J. M. (1996). Interactionbetween semantic and orthographic factors in conceptually driven naming: Comment on Starreveld and La Heij (1995), Journal of Experimental Psychology Learning Memory and Cognition, 22(1), 246-251.

Rofes, A., Mandonnet, E., de Aguiar, V., Rapp, B., Tsapkini, K., \& Miceli, G. (2019). Language processing from the perspective of electrical stimulation mapping. Cognitive Neuropsychology. https://doi.org/10.1080/02643294.2018.1485636.

Rosch, E., \& Mervis, C. B. (1975). Family resemblances: Studies in the internal structure of categories. Cognitive Psychology. https://doi.org/10.1016/0010-0285(75)90024-9. 
Rühl, D., Bölte, S., Feineis-Matthews, S., \& Poustka, F. (2004). Diagnostische Beobachtungsskala für Autistische Störungen (ADOS). Bern: Huber.

Saldaña, D., Carreiras, M., \& Frith, U. (2009). Orthographic and Phonological Pathways in Hyperlexic Readers with Autism Spectrum Disorders. Developmental Neuropsychology, 34(3), 240-253. https://doi.org/10.1080/87565640902805701.

Satzger, W., Fessmann, H., \& Engel, R. R. (2002). Liefern HAWIER, WST und MWT-B vergleichbare IQ-Werte? Zeitschrift Für Differentielle Und Diagnostische Psychologie. https://doi. org/10.1024//0170-1789.23.2.159.

Schmidt, K.-H., \& Metzler, P. (1992). WST Wortschatztest. Weinheim: Beltz Test GmbH.

Seidenberg, M. S., \& McClelland, J. L. (1989). A distributed, developmental model of word recognition and naming. Psychological Review. https://doi.org/10.1037/0033-295X.96.4.523.

Smadja, F. A. (1989). Lexical co-occurrence: The missing link. Literary and Linguistic Computing. https://doi.org/10.1093/ $1 \mathrm{cc} / 4.3 .163$

Spek, A., Schatorjé, T., Scholte, E., \& van Berckelaer-Onnes, I. (2009). Verbal fluency in adults with high functioning autism or Asperger syndrome. Neuropsychologia, 47(3), 652-656. https://doi.org/10.1016/j.neuropsychologia.2008.11.015.

Stanford NLP Group. (2019). https://partofspeech.org/.

Starreveld, P. A., \& La Heij, W. (1996). Time-course analysis of semantic and orthographic context effects in picture naming. Journal of Experimental Psychology: Learning Memory and Cognition, 22(4), 896-918. https://doi. org/10.1037/0278-7393.22.4.896.

Tager-Flusberg, H., Paul, P., \& Lord, C. (2005). Language and communication in autism. In F. R. Volkmar, A. Klin, R. Paul, \& D. J. Cohen (Eds.), Handbook of autism and pervasive developmental disorders (3rd ed., pp. 335-364). Hoboken, NJ: Wiley.

Tager-Flusberg, H., \& Sullivan, K. (1995). Attributing mental states to story characters: A comparison of narratives produced by autistic and mentally retarded individuals. Applied Psycholinguistics, 16(3), 241-256. https://doi.org/10.1017/S0142716400007281.

Teh, E. J., Yap, M. J., \& Rickard Liow, S. J. (2018). Emotional processing in autism spectrum disorders: Effects of age, emotional valence, and social engagement on emotional language use. Journal of Autism and Developmental Disorders. https://doi. org/10.1007/s10803-018-3659-x.

Tremblay, P., \& Steven, A. (2017). Broca and Wernicke are dead, or moving past the classic model of language neurobiology. Brain and Language, 162, 60-71. https://doi.org/10.1016/j.bandl 2016.08.004.

Troyer, A. K., Moscovitch, M., \& Winocur, G. (1997). Clustering and switching as two components of verbal fluency: Evidence from younger and older healthy adults. Neuropsychology. https://doi. org/10.1037/0894-4105.11.1.138.

Turner, M. A. (1999). Generating novel ideas: Fluency performance in high-functioning and learning disabled individuals with autism. Journal of Child Psychology and Psychiatry, 40(2), 189-201. https://doi.org/10.1111/1469-7610.00432.

Verly, M., Verhoeven, J., Zink, I., Mantini, D., Peeters, R., Deprez, S., ... Sunaert, S. (2014). Altered functional connectivity of the language network in ASD: Role of classical language areas and cerebellum. NeuroImage. Clinical, 4, 374-382. https://doi. org/10.1016/j.nicl.2014.01.008.

Vonberg, I., Ehlen, F., Fromm, O., \& Klostermann, F. (2014). The absoluteness of semantic processing: Lessons from the analysis of temporal clusters in phonemic verbal fluency. PLOS ONE. https://doi.org/10.1371/journal.pone.0115846.

Walker, G. M., \& Hickok, G. (2016). Bridging computational approaches to speech production: The semantic-lexical-auditory-motor model (SLAM). Psychonomic Bulletin and Review. https://doi.org/10.3758/s13423-015-0903-7.

Wasserstein, R. L., \& Lazar, N. A. (2016). The ASA's statement on p-values: Context, process, and purpose. American Statistician. https://doi.org/10.1080/00031305.2016.1154108.

Welcome, S. E., \& Trammel, E. R. (2017). Individual differences in orthographic priming relate to phonological decoding skill in adults. Cognitive Processing, 18(2), 119-128. https://doi. org/10.1007/s10339-017-0793-x.

Whiteside, D. M., Kealey, T., Semla, M., Luu, H., Rice, L., Basso, M. R., et al. (2016). Verbal fluency: Language or executive function measure? Applied Neuropsychology: Adult, 23(1), 29-34. https ://doi.org/10.1080/23279095.2015.1004574.

Wiśniowiecka-Kowalnik, B., \& Nowakowska, B. A. (2019). Genetics and epigenetics of autism spectrum disorder-current evidence in the field. Journal of Applied Genetics. https://doi.org/10.1007/ s13353-018-00480-w.

Yarkoni, T., Balota, D., \& Yap, M. (2008). Moving beyond Coltheart's $\mathrm{N}$ : A new measure of orthographic similarity. Psychonomic Bulletin and Review. https://doi.org/10.3758/PBR.15.5.971.

Publisher's Note Springer Nature remains neutral with regard to jurisdictional claims in published maps and institutional affiliations. 